\title{
DESIGN RECOMMENDATIONS TO PREVENT GLOBAL OUT-OF-PLANE INSTABILITY OF RECTANGULAR REINFORCED CONCRETE DUCTILE WALLS
}

\author{
Farhad Dashti ${ }^{1}$, Rajesh P. Dhakal ${ }^{2}$ and Stefano Pampanin ${ }^{3}$
}

(Submitted February 2020; Reviewed June 2020; Accepted March 2021)

\begin{abstract}
Observations of out-of-plane (OOP) instability in the 2010 Chile earthquake and in the 2011 Christchurch earthquake resulted in concerns about the current design provisions of structural walls. This mode of failure was previously observed in the experimental response of some wall specimens subjected to in-plane loading. Therefore, the postulations proposed for prediction of the limit states corresponding to OOP instability of rectangular walls are generally based on stability analysis under in-plane loading only. These approaches address stability of a cracked wall section when subjected to compression, thereby considering the level of residual strain developed in the reinforcement as the parameter that prevents timely crack closure of the wall section and induces stability failure. The New Zealand code requirements addressing the OOP instability of structural walls are based on the assumptions used in the literature and the analytical methods proposed for mathematical determination of the critical strain values. In this study, a parametric study is conducted using a numerical model capable of simulating OOP instability of rectangular walls to evaluate sensitivity of the OOP response of rectangular walls to variation of different parameters identified to be governing this failure mechanism. The effects of wall slenderness (unsupported height-to-thickness) ratio, longitudinal reinforcement ratio of the boundary regions and length on the OOP response of walls are evaluated. A clear trend was observed regarding the influence of these parameters on the initiation of OOP displacement, based on which simple equations are proposed for prediction of OOP instability in rectangular walls.
\end{abstract}

\section{INTRODUCTION}

Structural walls, also known as shear walls, are one of the common lateral load resisting elements in reinforced concrete (RC) buildings in seismic regions. A relatively high stiffness is provided by a structural wall along its in-plane direction making it the main lateral force resisting system of the structure. As a result, this structural system needs to prevent damage to nonstructural elements during minor earthquakes, limit structural damage in moderate earthquakes and prevent the collapse of the building during major seismic events. To achieve this level of reliability, a structural wall needs to respond to seismic actions with enough ductility and energy dissipation capacity. Hence, any mode of failure that is bound to interfere with its operation must be impeded until the desired performance level is achieved. To achieve this goal, the failure modes that different types of structural walls are likely to sustain should first be identified and categorized.

In recent years, as design optimization and architectural spacing have gained importance, slender rectangular walls, taking less space and believed to be more economical, have become more common in many countries. The use of higher concrete strengths has also resulted in more slender profiles than those previously tested in the laboratory or in real buildings under earthquakes. The performance of these structural walls in the Chile (February 2010) and New Zealand (February 2011) earthquakes has exposed some problems with the existing design of RC structural walls. OOP instability is one of the failure patterns observed in $\mathrm{RC}$ wall buildings in the Canterbury earthquakes [1]. This failure pattern refers to buckling of a portion of a wall section OOP as a result of either pure in-plane loading or a combination of in-plane and OOP (i.e. bidirectional) loading. This buckling under in-plane loading is limited to an end-region of the wall, where the axial strains from in-plane loading are the greatest.

The structures with instability failure in walls are hardly repairable since this mode of failure induces a considerably abrupt loss of lateral load resistance, which can cause instability of the whole building. Paulay and Goodsir [2] and Paulay and Priestley [3] were the first to describe in detail the development of OOP instability failure. As there were not many test results on this mode of failure, some assumptions such as the height of the wall involved in the formation of instability (i.e. buckling length) were made in these postulations.

Paulay and Priestley [3] scrutinized the mechanism of OOP instability by idealization of the part of the wall height that has undergone OOP deformation with a circular shape. By expressing the lateral displacement $\delta$ in terms of the wall thickness $b$, i.e., $\delta=\xi b$, and using expressions developed for estimation of the radius of curvature, the eccentricity ratio $\xi$ was calculated as:

$$
\xi=\frac{\varepsilon_{s m}}{8 \beta}\left(\frac{l_{o}}{b}\right)^{2}
$$

where,

$\varepsilon_{s m}=$ the maximum tensile strain of the longitudinal reinforcement (the relatively small elastic recovery was neglected and the residual strain was assumed to be of the order of $\left.\varepsilon_{s m}\right)$.

$l_{o}=$ the height along which OOP instability develops and assumed to be equal to the theoretical length of the plastic hinge

$\beta b=$ the distance from the layer of elastic reinforcement to the point of initial crack closure.

\footnotetext{
${ }^{1}$ Corresponding Author, Research Associate, Quake Centre, University of Canterbury, Christchurch, New Zealand, farhad.dashti@ canterbury.ac.nz (Member)

2 Professor, University of Canterbury, Christchurch, rajesh.dhakal@ canterbury.ac.nz (Fellow)

${ }^{3}$ Professor, Department of Structural and Geotechnical Engineering, Sapienza University of Rome, Italy; Adjunct Professor, Department of Civil and Natural Resources Engineering, University of Canterbury, Christchurch, New Zealand, stefano.pampanin@uniromal.it (Fellow)
} 
The section equilibrium was used to establish a stability criterion for the section undergoing OOP deformations as:

$$
\begin{aligned}
& \xi \leq \xi_{c}=0.5\left(1+2.35 m-\sqrt{5.53 m^{2}+4.70 m}\right) \\
& \text { where, } \\
& m=\rho f_{y} / f_{c}^{\prime}
\end{aligned}
$$

According to Paulay and Priestley [3], with increasing reinforcement content, instability must occur at a reduced eccentricity $\delta=\xi b$. The plastic hinge length, $l_{p}$ (given by Equation 4), was postulated to be a reasonable approximation of the potential height of the wall over which OOP buckling may occur, $l_{o}$.

$$
l_{p}=0.2 l_{w}+0.044 h_{w}
$$

where,

$l_{w}=$ horizontal length of the wall section

$h_{w}=$ full height of the cantilever wall

Paulay and Priestley [3] introduced an upper bound limit for development of OOP instability, as well. Regardless of the stability criterion mentioned above, OOP instability of the section was postulated to occur if the lateral displacement exceeds half of the wall thickness.

The current New Zealand design provisions (NZS3101 2006A3 [4]) for prevention of this mode of failure are based on the equations derived in these past studies. The basic findings of these studies were confirmed by Chai and Elayer [5], who investigated the OOP instability of structural walls by testing concrete columns that represented boundary zones of rectangular walls. This method has become a common approach for investigating this mode of failure [6-13]. However, many assumptions need to be made such as: a) the wall region that undergoes the OOP instability, b) the boundary conditions at the top, bottom and along the edge that joins the boundary zone to the central wall panel, and c) the height of the wall involved in the formation of OOP instability.

Chai and Elayer [5] studied the OOP instability of ductile RC walls by idealizing the end-region of the wall as an axially loaded RC column, and conducted an experimental study to examine the OOP instability of several RC columns designed to represent the end-regions of a ductile planar $\mathrm{RC}$ wall under large amplitude reversed cyclic tension and compression.

Chai and Elayer [5] used the same stability criterion as Equation 3 and considered three components for $\varepsilon_{s m}$ as:

$$
\begin{gathered}
\varepsilon_{s m}=\varepsilon_{e}+\varepsilon_{r}+\varepsilon_{a}^{*} \\
\varepsilon_{s m}=\eta_{1} \varepsilon_{y}+\eta_{2} \varepsilon_{y}+\varepsilon_{a}^{*}
\end{gathered}
$$

where,

$\varepsilon_{e}=$ an elastic strain recovery for the unloading from a tensile excursion;

$\varepsilon_{r}=$ a reloading strain associated with compression yielding of the reinforcement (and depends on the cyclic characteristic of the reinforcing steel since a reduced stiffness in the steel is expected due to the Bauchinger'strain effect)

$\varepsilon_{a}^{*}=$ an axial strain at first closure of cracks

Based on the relationship of the transverse curvature at midheight of the column with the mid-height OOP displacement and axial strain corresponding to the first crack closure the following kinematic relation was derived:

$$
\varepsilon_{a}^{*}=\left(\frac{1}{2 c}\right)\left(\frac{b}{l_{o}}\right)^{2} \xi_{m}
$$

where, $c$ depends on the transverse curvature distribution of the column and $\xi_{m}$ is the OOP displacement at mid-height of the column normalized by the wall thickness.

The following assumptions were made:

- The OOP displacement for the crushing limit state was assumed to be fairly close to the OOP displacement at first crack closure.

- The limit state for calculation of the OOP displacement was concrete crushing. i.e. the OOP displacement should be limited to $\xi_{c}$ (the OOP displacement corresponding to the concrete crushing).

- $\quad \eta_{1}=1.0$, and $\eta_{2}=2.0$

- The curvature distribution was considered sinusoidal, i.e., coefficient $c=1 / \pi^{2}$

Based on these assumptions, the maximum tensile strain that may be imposed on the longitudinal reinforcement was written as:

$$
\varepsilon_{s m}=\frac{\pi^{2}}{2}\left(\frac{b}{l_{o}}\right)^{2} \xi_{c}+3 \varepsilon_{y}
$$

The OOP instability failure was observed and measured in several experiments. Rosso et al [14] provided an inclusive summary of these experiments which were conducted by Oesterle et al [15], Goodsir [16], Thomsen and Wallace [17], Johnson [18] and Rosso et al [19]. This data showed that all collected test units had some common features in their response; in particular, reaching the same order of magnitude of maximum tensile strains, and observation of the maximum out-of-plane displacement at approximately $0 \%$ in-plane drift. Rosso et al [14] investigated the out-of-plane failure mode of walls by analyzing the response of two singly reinforced walls tested under cyclic loading as part of an experimental campaign on five thin T-shaped walls [20]. The specimens were identical but were subjected to two different in-plane and bidirectional loading patterns. One of the issues that was well elaborated in this study was the difference between the effective buckling length assumed in the analytical models and the one observed in the test. Rosso et al [14] observed that the application of an out-of-plane displacement at the top of the wall increases the global out-of-plane deformation if it is applied in the opposite direction of the latter and vice versa. The effects of different parameters on the instability of singlyreinforced walls is also studied by Rosso et al [21]. The evolution of out-of-plane instability was also observed in several limited ductile walls tested by Menegon et al [22]. The specimens had a height-to-thickness ratio of approximately 15 and were designed to be representative of Australian construction practice.

The authors have scrutinized the mechanism of global OOP instability failure in RC walls and the controlling parameters using both numerical (FEM) and experimental studies. A brief summary of objectives within this study and the methodology employed to achieve them is provided in Table 1. A numerical model employing the curved shell elements available in the commercial finite element analysis software DIANA [23] was proposed for simulation of different failure modes of RC rectangular walls including OOP instability [24], which was the first modelling approach that could simulate this mode of failure without introduction of artificial eccentricity. A comprehensive validation of the model was conducted which mainly focused on verification of the OOP instability simulated by the model using results of several tested wall specimens, a 
blind prediction as well as a parametric study [25-28]. The response of several wall specimens that exhibited various failure mechanisms in the laboratory was also simulated by this model within the modelling group of the Virtual International Institute for Performance Assessment of Structural Wall (NSF SAVI Wall Institute) [29].

The effects of different parameters on OOP instability of doubly reinforced walls were qualitatively investigated using both extensive FEM simulations and experimental tests $[14,15]$. The effect of slenderness (unsupported height-to-thickness) ratio, reinforcement ratio, length and axial load on the strain history and stress-strain response of the longitudinal bars throughout the cyclic loading, as well as the strain gradient along the wall height was evaluated, and the variation of the OOP response associated with variation of each parameter was discussed.
According to Dashti et al [14], for a given set of slenderness (unsupported height-to-thickness) and reinforcement ratios, development of a critical average tensile strain over a certain height can lead to formation of OOP instability in walls. Therefore, in addition to its value, the distribution of tensile strain along the height of the wall boundary region is identified as a key parameter affecting the likelihood of OOP instability [9,14-17]. In this study, a parametric study is conducted to quantitatively evaluate the effect of slenderness and reinforcement ratios as well as the parameters that govern the strain gradient along the wall height (such as wall length) on generation of ideal circumstances for development of OOP instability. An equation is ultimately derived for calculation of the maximum slenderness to safeguard against development of OOP instability up to a desired drift level.

Table 1: Global out-of-plane instability of walls: Project aims and methodology.

\begin{tabular}{ll}
\hline Aim & Methodology \\
\hline $\begin{array}{l}\text { Gain an in-depth understanding of the global } \\
\text { out-of-plane instability/buckling mechanism, } \\
\text { including the effect of governing parameters } \\
\begin{array}{l}\text { such as wall section thickness, length, axial } \\
\text { load and longitudinal reinforcement ratio. }\end{array}\end{array}$ & $\begin{array}{l}\text { A numerical study to develop a modelling approach capable of } \\
\text { capturing different failure modes of structural walls including the } \\
\text { global out-of-plane instability/buckling mechanism. }\end{array}$ \\
\cline { 2 - 2 } & $\begin{array}{l}\text { A numerical parametric study on the out-of-plane response of singly } \\
\text { and doubly reinforced concrete walls using the verified modelling } \\
\text { approach to link the effects of the key wall parameters with } \\
\text { progression of out-of-plane instability. }\end{array}$
\end{tabular}

Ref.

[24-26, approach to link the effects of the key wall parameters with

Verify the theory of the out-of-plane instability Experimental testing of four slender rectangular walls ranging in thickness, length and axial load and comparison of the observations with the FEM predictions.

$[32-35]$ mechanism through experimental testing.

Comparison of wall instability observed in earthquakes and experimental testing (including the above-noted four RC wall tests)

Verify existing analytical models for the globa out-of-plane instability/buckling mechanism and evaluate the suitability of the existing requirements in NZS 3101:2006-A3 for prevention of out-of-plane instability.

\section{FAILURE MECHANISM AND CONTROLLING PARAMETERS}

\section{Salient Features of OOP Instability}

The key observations made in the numerical and experimental studies on the evolution of OOP deformation and subsequent instability in rectangular $\mathrm{RC}$ walls are summarised as below.

- The OOP response of walls was found to have four stages of: i) minimal or no, ii) fully recoverable, iii) partially recoverable and iv) irrecoverable OOP deformation. The magnitude of tensile strain in longitudinal reinforcement in previous cycles was identified to be the factor governing the development of these stages. Figure 1 shows the evolution and recovery of OOP deformation (Stage ii) predicted by the numerical model. Stages iii and iv were found to be in correlation with the stability criterion and upper bound limits proposed by Paulay and Priestley [3], respectively. Figure 2 indicates development of these stages in one of the wall specimens tested by the authors [37]. Stage iv would result in abrupt strength degradation of the wall and possibly collapse of the structure. Therefore, the stability criterion (Equation 3) could be used to define the limit state for the tensile strain of the boundary region longitudinal bars. It should be noted that this strain is the average tensile strain developed along the buckling length, which is understandably lower than the maximum tensile strain at the wall base. Therefore, the approaches commonly used for estimating the maximum strain at the wall base that assume plane sections to remain plane cannot be used to provide a correlation between this critical strain and the drift level.

- The equation proposed by Paulay and Priestley [3] and Chai and Elayer [5] for calculation of the tensile strain corresponding to this stability criterion included buckling length as a key parameter, which was assumed to be equal to the length of the plastic hinge. However, in the walls tested by the authors [37] and several others [18, 14] it was observed that the buckled length can exceed the plastic hinge length by more than a factor of two. Substitution of the experimentally observed buckling length in the equations proposed by Paulay and Priestley [3] and Chai and Elayer [5] resulted in significantly more accurate estimation of the tensile strain corresponding to the stability criterion [37].

- Aside from the magnitude of the tensile strain in the longitudinal reinforcement, the distribution of tensile strain along the wall height was also found to be a critical parameter in the evolution of OOP deformation. For a given average tensile strain along the height of the plastic region, localized tensile strain at the base might induce bar fracture, bar buckling and accelerated concrete crushing, resulting in a local instability during the subsequent loading cycles [39]. Comparatively, a relatively uniform 
strain distribution along the height of the plastic region can induce compression yielding of the bars along this height and lead to the global OOP instability. Based on these experimental observations and the modes of instability failure documented in the literature, the OOP response of walls is classified into five different modes [38]. Among these, the global OOP instability (Figure 2) is the only mode that results in abrupt strength degradation of the wall and is associated with development of large strains along a sufficient height of the wall from the base. Therefore, doubly-reinforced rectangular walls with well-confined boundary regions and high longitudinal and horizontal reinforcement ratios are susceptible to the abrupt global OOP instability failure if they are able to develop large tensile strains along the height of the plastic region before progression of other failure modes (such as bar buckling, bar fracture and concrete crushing) and before progression of large diagonal cracks along the web. If other failure modes occurred earlier, they can interact with development and recovery of OOP deformation and result in a more localized instability that can be classified as a secondary mode of failure.
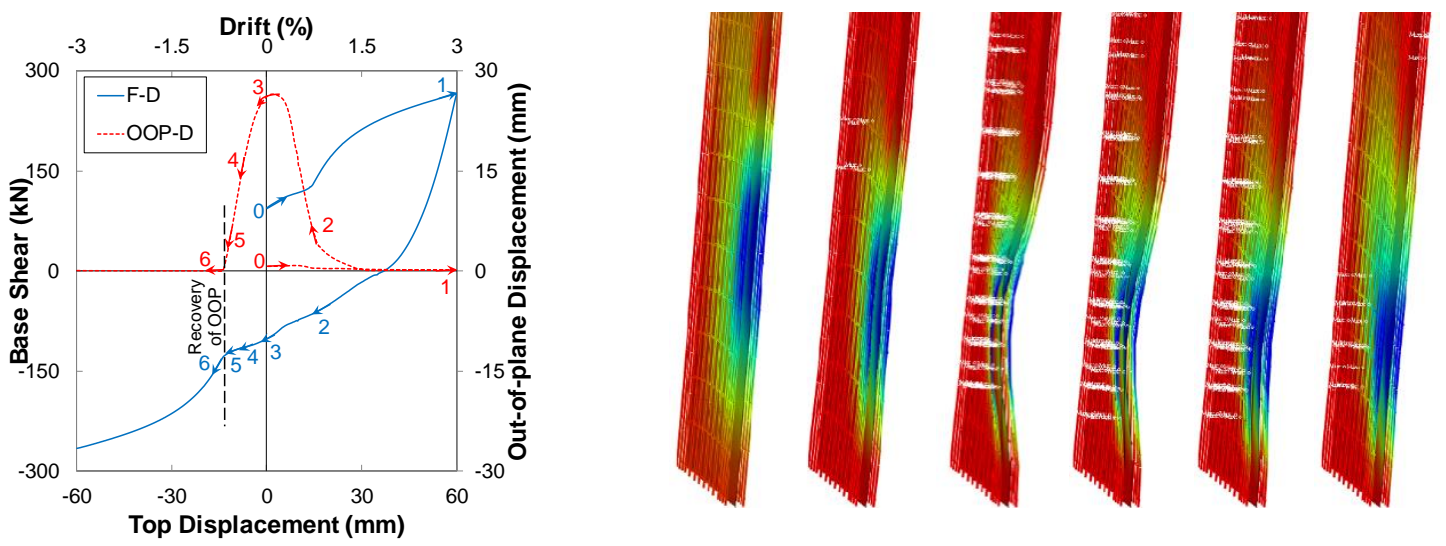

1
- Slope of the tensile strain profile along the height of the boundary regions generally changes dramatically at an elevation from the base, generating larger strains at the zone located below this elevation. This elevation increases with the applied drift level, and the OOP deformation starts when its value reaches about $60 \%$ of the unsupported height of the wall. The buckling length at each stage is equal to this elevation and is limited to $70-75 \%$ of the unsupported height when the stability criterion is reached. It should be mentioned that the type of restraint at the storey level that allows rotation in the OOP direction as well as the type of strain gradient along the wall height would affect the buckling length. The fully fixed boundary conditions with a strain gradient that is fairly uniform along the height (similar to the one of the isolated boundary zones under tensile-compressive cycles [12]) limits the buckling length to $60 \%$ of the unsupported height. However, if there is no restraint provided at the storey level against the rotation in the OOP direction, as was the case in some wall experiments [15], the buckling length would be close to the whole unsupported height of the wall [26].

Figure 1: The progression and recovery of OOP deformation simulated by curved shell finite element model.

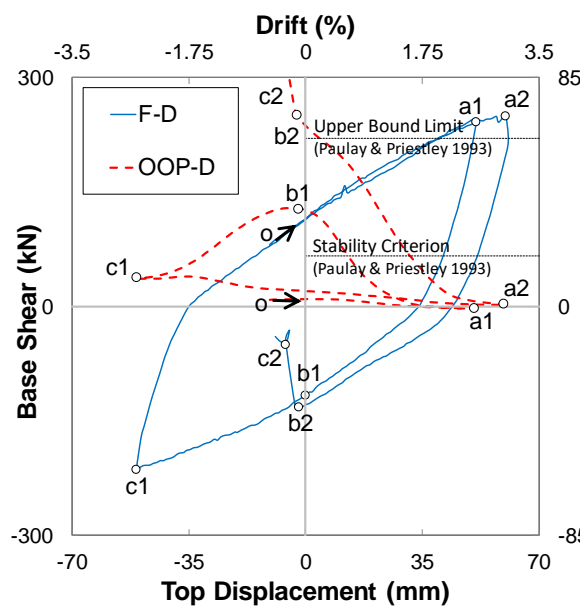

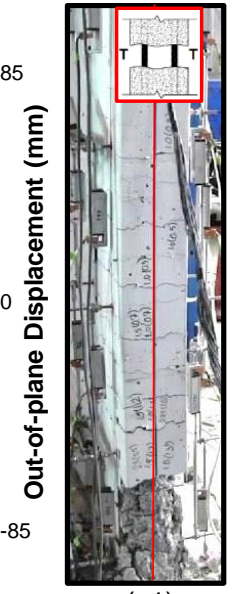

(a1)

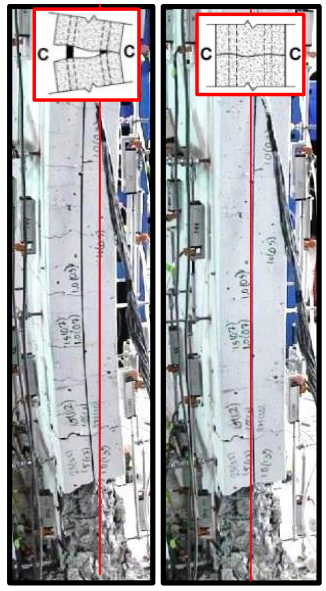

(b1)

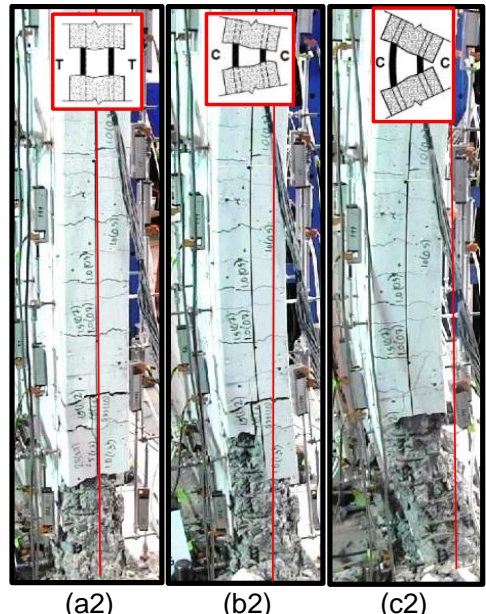

(a2) (c2)

Figure 2: Evolution of OOP deformation and subsequent global instability-Experimental observation.

\section{Qualitative Effects of the Key Parameters}

Based on the numerical and experimental parametric studies $[27,31,35]$, the controlling parameters were classified into: i) slenderness (unsupported height-to-thickness) ratio; ii) the parameters that govern the vertical strain history and vertical strain gradients (e.g. axial load, N; wall length, L; longitudinal reinforcement ratio, $\rho_{v}$; concrete strength, $f_{c}^{\prime}$; loading history, shear-span ratio, etc.) and iii) OOP boundary conditions and different sources of eccentricity. These parameters were found to have the following influences on the OOP response of rectangular walls:

- Increasing the wall thickness, i.e. decreasing the slenderness (height-to-thickness) and length-to-thickness ratios, results in earlier crack closure for a given quantity of previously induced tensile strain and is the most efficient approach to delay progression of $\mathrm{OOP}$ deformation. 
- The reduction of wall length results in development of smaller tensile strains in the boundary region for a given drift level, and is therefore able to delay progression of OOP deformation. The nonlinearity of strain gradients along the wall length, however, may decrease this effect [40].

- Depending on the stage of loading, the axial load ratio can have a mixed effect on the development of OOP wall instability. Any level of compressive axial load can be beneficial in delaying the development of OOP buckling because the tensile strain in longitudinal reinforcement (key trigger for initiation of OOP deformation) is decreased. Conversely, once the longitudinal reinforcement strain exceeds the critical tensile strain (i.e., tensile strain after which global OOP eccentricity is generated), any magnitude of compressive axial load can become detrimental by generating a P-Delta moment that accelerates the OOP deformation of the section.

- Higher longitudinal reinforcement ratio results in delay of crack closure and leads to fatter hysteretic curves, increasing the energy required for the in-plane deformation when compared to that for OOP deformation, particularly in a cracked wall section that the OOP stiffness is reduced due to yielding of the bars under compressive stresses. As discussed by Paulay and Priestley [3], the increase of longitudinal reinforcement ratio also decreases the OOP deformation corresponding to instability of the section (stability criterion) and therefore results in more susceptibility of walls to OOP instability.

- The effect of concrete strength on the in-plane and OOP responses of walls is studied using numerical and experimental investigations by Tripathi et al. [41]. The concrete strength is found to influence the strain gradients along the wall length by changing the neutral axis depth for a given curvature. The strain gradients along the height of walls are also affected by this parameter since higher compressive strength of concrete can understandably result in larger strains along the wall height up to a higher elevation from the base. This causes the bars to yield in compression within a greater height during reloading of the cracked wall section in compression, which consequently increases the likelihood of development of OOP deformation.

- The progression of OOP deformation is more likely to occur in walls with higher shear strength as the contribution of flexure to the total top displacement is higher in these cases.

- The OOP rotational stiffness provided by the floor system (at the storey level) would have a noticeable impact on the initiation and extent of the OOP deformation. The hingedfixed boundary conditions can result in two times larger OOP displacement compared to the fixed-fixed constraints although the OOP boundary conditions at the floor level would be neither fully fixed nor fully hinged.

- The effect of eccentricity generated by the difference in inelastic response of the longitudinal bars across the wall thickness on the OOP response of walls cannot be neglected given the key role of longitudinal bars in resisting the compression induced during the loading reversal in a cracked wall section.

- Walls with a single layer of longitudinal reinforcement are more susceptible to instability failure compared to the doubly reinforced ones. This is because following development of large tensile strains, a single layer of vertical reinforcement under compressive stresses of reversed loading lacks a mechanism to restore stability when the cracks are still wide open. Also, being a singly reinforced wall, the eccentricity of longitudinal reinforcement with respect to the loading plane influence the out-of-plane response and result in its earlier initiation. However, its effect during the final stages of the wall response and formation of out-of-plane instability is not very significant.

\section{NEW ZEALAND CODE REQUIREMENTS}

The OOP buckling of slender walls is addressed in Section 11.4.3 (Dimensional Limitations) of the New Zealand standard [42]. For walls with axial force levels greater than $0.05 f_{c}^{\prime} A_{g}$ and for ductile or limited ductile plastic region the thickness in the boundary region of the wall section, extending over the lesser of the plastic hinge length or the full height of the first storey, shall not be less than

$$
\mathrm{t}_{\mathrm{m}}=\frac{\alpha_{\mathrm{r}} \mathrm{k}_{\mathrm{m}} \beta\left(\mathrm{A}_{\mathrm{r}}+2\right) \mathrm{L}_{\mathrm{w}}}{1700 \sqrt{\bar{\xi}}}
$$

where,

$\alpha_{\mathrm{r}}=1.0$ for doubly reinforced walls and 1.25 for singly reinforced walls; and

$\beta=5$ for limited ductile plastic regions

$\beta=7$ for ductile plastic regions

$\mathrm{A}_{\mathrm{r}}=$ aspect ratio of wall $\left(\mathrm{h}_{\mathrm{w}} / \mathrm{L}_{\mathrm{w}}\right)$

$\mathrm{k}_{\mathrm{m}}=1.0$, unless it can be shown that for long walls:

$$
\mathrm{k}_{\mathrm{m}}=\frac{\mathrm{h}_{\mathrm{n}}}{\left(0.25+0.055 \mathrm{~A}_{\mathrm{r}}\right) \mathrm{L}_{\mathrm{w}}}<1.0
$$

and

$$
\xi=0.3-\frac{\rho_{\mathrm{l}} \mathrm{f}_{\mathrm{y}}}{2.5 \mathrm{f}_{\mathrm{c}}^{\prime}}>0.1
$$

where,

$\rho_{l}=$ vertical reinforcement ratio of the boundary region

$h_{n}=$ clear vertical height between floors or other effective lines of lateral support

According to Section C11.4.3.1 [42], where the buckling length, assumed to be equal to the theoretical length of the plastic hinge, approaches or exceeds the unsupported height of the wall in the first storey, the limitation of Equation 9 becomes overly severe. In such cases, which are encountered when the length of a wall relative to the height of the first storey becomes large, it is assumed that the buckling length is equal to $80 \%$ of the clear unsupported height of the wall. This is accounted for by Equation 10 .

As discussed in Section 2.2, the effect of axial load on the formation and development of OOP deformation is not straightforward. Higher axial loads can prevent development of high residual strains in the reinforcement and contribute to crack closure to occur before any OOP deformation can initiate. However, if this crack closure does not happen on time, higher axial loads can trigger faster progression of OOP deformation by increasing the P-delta effect. Therefore, the design provisions relevant to OOP instability need to apply for walls with all levels of axial force, including the levels smaller than $0.05 f_{c}^{\prime} A_{g}$. 


\section{QUANTITATIVE EFFECTS OF THE KEY PARAMETERS}

The effects of different parameters on the OOP response of doubly reinforced rectangular structural walls were addressed by the authors [31]. The parameters known to be influencing the OOP response of rectangular walls were studied using parametric models generated for three slender wall specimens tested in the literature. A parametric study was also conducted on a wall specimen that was designed for experimental investigation of this mode of failure. The numerical predictions were compared with the experimental response of the four wall specimens that were tested [35]. The properties of these parametric wall models are given in Table 2.

In this section, a parametric study is conducted using the verified numerical model to quantitatively evaluate effects of the parameters identified to influence the OOP response of walls. The parametric wall models were different from the benchmark wall in terms of length, reinforcement ratio and thickness. It should be noted that the OOP rotation at the storey level was considered to be fixed in the numerical model. As for axial load, a separate parametric analysis was conducted to find out the critical axial load ratio for each case. The benchmark wall had the characteristics similar to Specimen RWB, which was tested by the authors [34]. The properties of these parametric wall models are given in Tables 3-7. The length of the walls was varied to generate $\mathrm{L} / \mathrm{H}$ ratios ranging from 1 to 3 . For each $\mathrm{L} / \mathrm{H}$ ratio, the slenderness ratios varied from 10 to 28 by changing the thickness of the wall. It should be mentioned that the distance between the two layers of reinforcement was also increased accordingly. As discussed by the authors [31], the distance between the two layers of reinforcement does affect the OOP response of rectangular walls. Three levels of reinforcement ratio were considered for the boundary regions, namely low (0.013), medium (0.026) and high (0.052). For all these cases, the critical strain was determined using a trial and error algorithm.

As described in Section 2.1, the stability criterion that was developed in the analytical models was found to be associated with Stage iii (partially recoverable OOP deformation) of the OOP response of walls and is therefore used as a threshold for definition of the critical strain in this study. Thus, the critical strain is defined as the maximum tensile strain (at peak displacement during loading) at the elevation where the maximum OOP displacement equivalent to the stability criterion is developed after unloading and during reloading in the opposite direction. The loading program comprised two cycles per drift level, and the applied lateral displacement was increased so as to generate the maximum OOP displacement corresponding to the stability criterion. The critical strains and corresponding drift levels numerically predicted for all the wall models are presented in Tables 3-7.

The critical strain versus slenderness ratio is plotted in Figure $3 \mathrm{a}$ and Figure $3 \mathrm{~b}$ for different values of $\mathrm{L} / \mathrm{H}$ and reinforcement ratio, respectively. There was a clear trend for the scatters of each set of parametric study and can be represented using a parabolic function, which generated the best trend line. Figure $3 \mathrm{c}$ displays the critical strain versus drift capacity. The drift capacity versus slenderness ratio is plotted in Figure $3 \mathrm{~d}$ and Figure $3 \mathrm{e}$ for the variation of $\mathrm{L} / \mathrm{H}$ and reinforcement ratio, respectively.

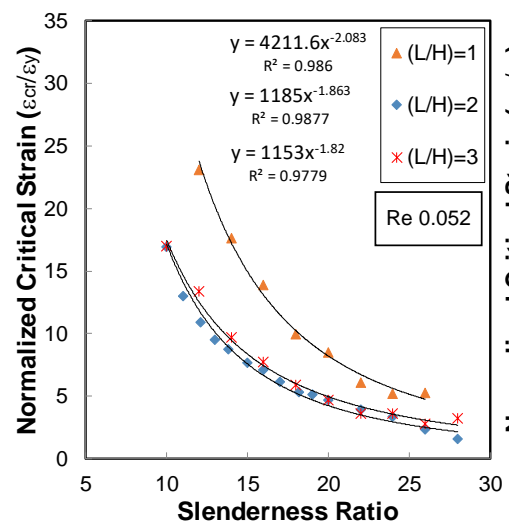

(a)



(b)

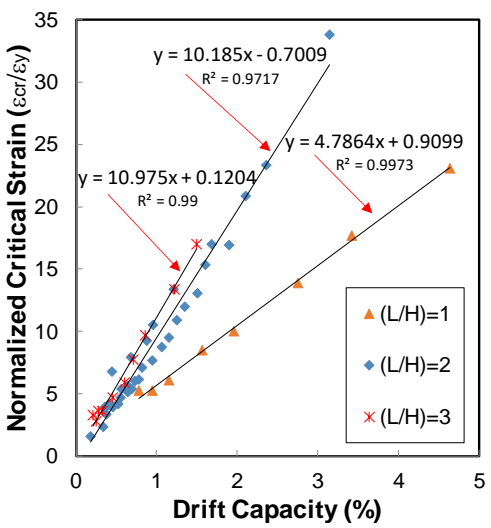

(c)

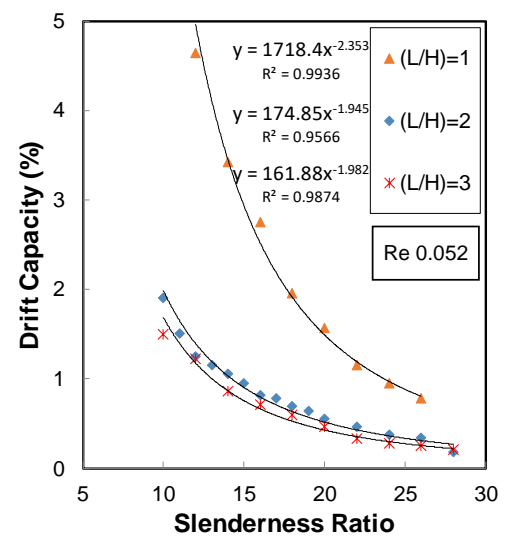

(d)



(e)

Figure 3: (a) \& (b) Effect of wall length and reinforcement ratio on the critical strain vs slenderness ratio; (c) critical strain vs drift capacity; (d) \& (e) ) Effect of wall length and reinforcement ratio on drift capacity vs slenderness ratio. 
As can be seen in Figure 3c, the critical strain increases linearly with respect to the drift capacity although the trend line is significantly different between $\mathrm{L} / \mathrm{H}$ ratio of 1 and $\mathrm{L} / \mathrm{H}$ ratios equal to or greater than 2 . It should be noted that this critical strain corresponds to the extreme tension fibre of the wall length and the elevation corresponding to the maximum OOP displacement. Given the nonlinearity of strain gradients along the wall length [40], the variation of strain with the increase of wall length for a given drift level does not follow a linear trend, and the assumption of "plane sections remain plane" would not be applicable to relatively long walls. Besides, the analytical models based on linear strain gradients would merely calculate the strain at the base and empirical equations need to be used to obtain the strain at the elevation of the maximum OOP displacement. Therefore, the following equations, derived based on the numerical predictions, could be used to correlate the normalized critical strain at the elevation of maximum OOP displacement with the drift level.

where,

$$
\frac{\varepsilon_{c r}}{\varepsilon_{y}}=\frac{500}{\alpha} D
$$

$\mathrm{D}=$ drift level

$\alpha=\frac{H}{L}$ for $\frac{L}{H} \leq 2$ and $\alpha=0.5$ for $\frac{L}{H}>2$

Figure 4 displays the maximum tensile strain gradients corresponding to the critical strain, the strain gradients corresponding to the onset of OOP deformation and the OOP displacement profiles for different $\mathrm{L} / \mathrm{H}$ and slenderness ratios.
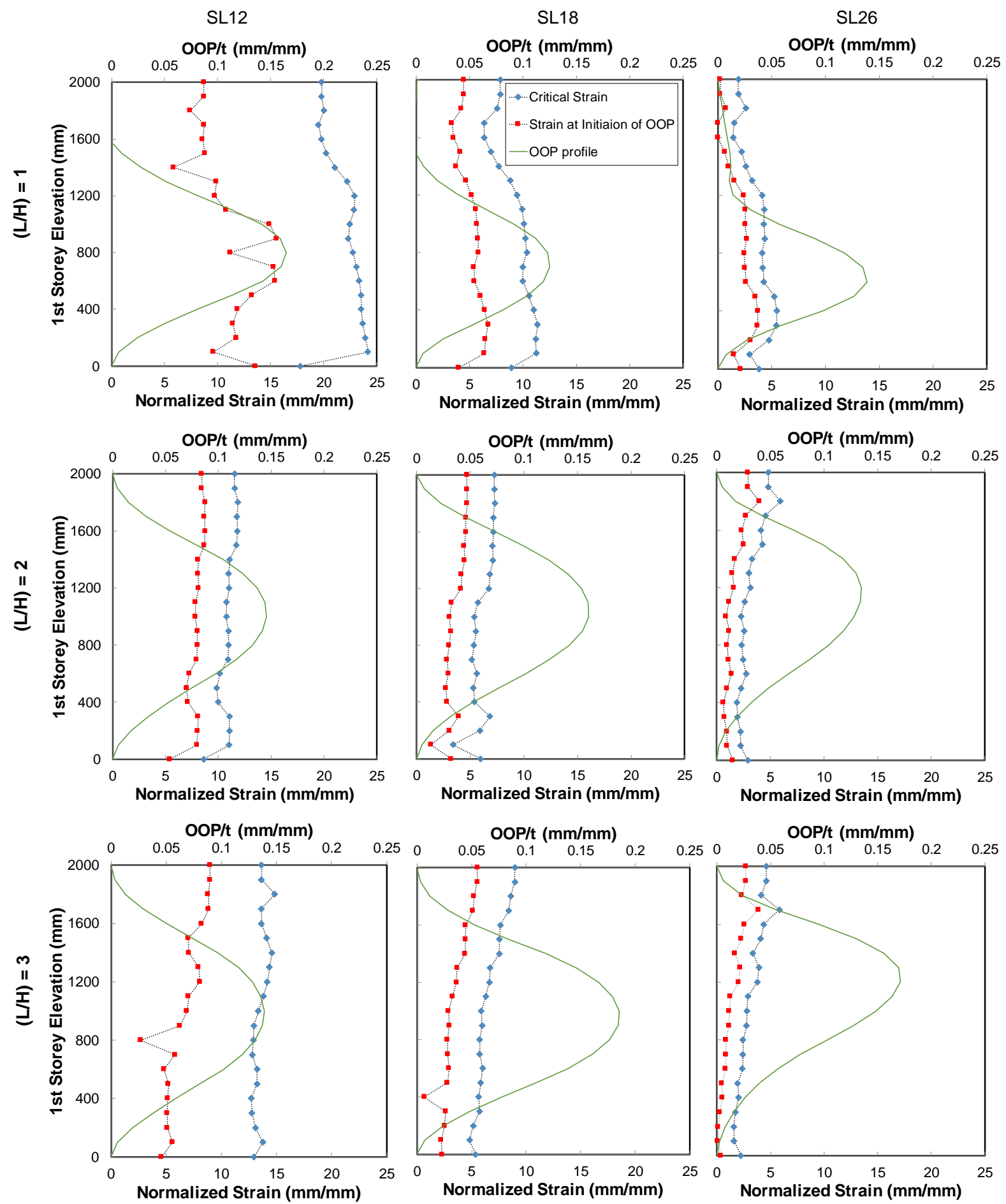

Figure 4: Effect of wall length and slenderness on the strain gradients along the wall height and the OOP displacement profile. 


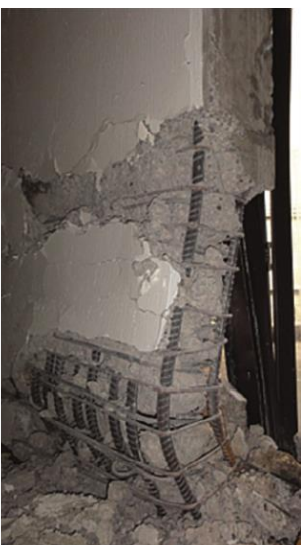

(a)

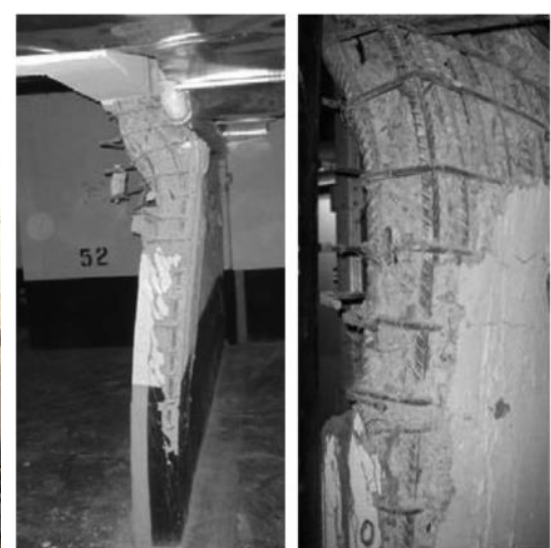

(b)

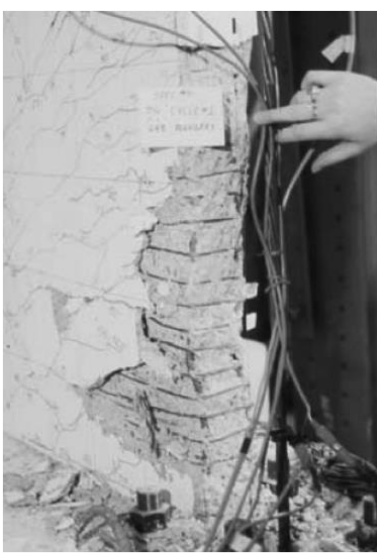

(c)

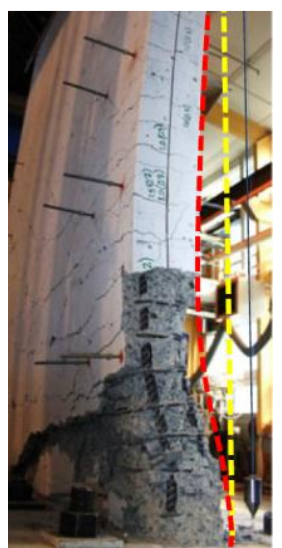

(d)

Figure 5: (a) Wall instability with the maximum OOP displacement close to the base [44]; (b) wall instability with the maximum OOP displacement at a relatively high elevation from the base [45]; (c) Specimen TW2 web boundary instability [46]; (d) global instability of Specimen RWL [37].

As can be seen in this figure, the increase of slenderness results in the reduction of the buckling length. Given the significant difference in the slenderness values used for this comparison, the variation of the buckling length must not be very noticeable when the variation of slenderness is not substantial. As for the increase in wall length $(\mathrm{L})$ for a given unsupported height $(\mathrm{H})$ (i.e. the increase of $\mathrm{L} / \mathrm{H}$ ratio), the distribution of maximum vertical tensile strains along the height of the boundary regions becomes more uniform with the increase of $\mathrm{L} / \mathrm{H}$ from 1 to 2 . The variation of this ratio from 2 to 3 , however, does not significantly affect these strain gradients. The OOP displacement profiles corresponding to the $\mathrm{L} / \mathrm{H}$ equal to 2 and 3 are therefore different from the $\mathrm{L} / \mathrm{H}$ equal to 1 , with the maximum OOP displacement values predicted at higher elevations from the base. With the increase of slenderness in these cases, the maximum OOP displacement occurs closer to the top of the unsupported height (storey level). This type of OOP response was observed in the 2010 Chile earthquake (Figure 5b), while the OOP displacement profiles of the models with $\mathrm{L} / \mathrm{H}=1$ are in line with the global instability of an L-shaped wall failed during the 2011 New Zealand earthquake (Figure 5a). It is worth noting that, due to the space and loading restrictions of the experimental facilities, flexure-dominated specimens (shear-span rations greater than 2.5) with $\mathrm{L} / \mathrm{H}>1.0$ are rarely tested and hence missing in the literature. Therefore, the maximum OOP displacement of the tested specimens is generally observed close to the base, where the relatively large tensile strains are distributed. Figure $5 \mathrm{c}$ and Figure $5 \mathrm{~d}$ indicate the OOP instability of two wall specimens with $\mathrm{L} / \mathrm{H}=0.3$ and 0.8 , respectively.

Figure 6 and Figure 7 display the distribution of vertical strains before initiation of OOP deformation as well as the OOP deformation pattern for relatively slender wall models (slenderness ratio of 26) with $\mathrm{L} / \mathrm{H}=1.0$ and $\mathrm{L} / \mathrm{H}=2.0$, respectively. The vertical strains higher than the yield strain $(0.002)$ are indicated in these figures. The distribution of vertical strains that are greater than the yield strain at the onset of OOP deformation indicates the extent of wide cracks throughout the wall area and the potential zone of yielding in compression before crack closure. As can be seen in these figures, the OOP deformation pattern and the buckling length is understandably in line with the extent of wide cracks along the wall height and the potential zone of yielding in compression during loading reversal. Therefore, for a given unsupported height, $\mathrm{H}$, the increase of wall length would affect the OOP response by both increase of the maximum tensile strain for a given drift and variation of the strain distribution pattern. However, as the plastic region extends above the unsupported height ( $1^{\text {st }}$ storey height) of the wall, the increase of wall length would not have a significant effect on the strain distribution profile. Given the nonlinearity of strain gradients along the length of walls, the value of the average tensile strain along the height of the $1^{\text {st }}$ storey would not change as extensively as it would with variation of $\mathrm{L} / \mathrm{H}$ from 1 to 2 either.

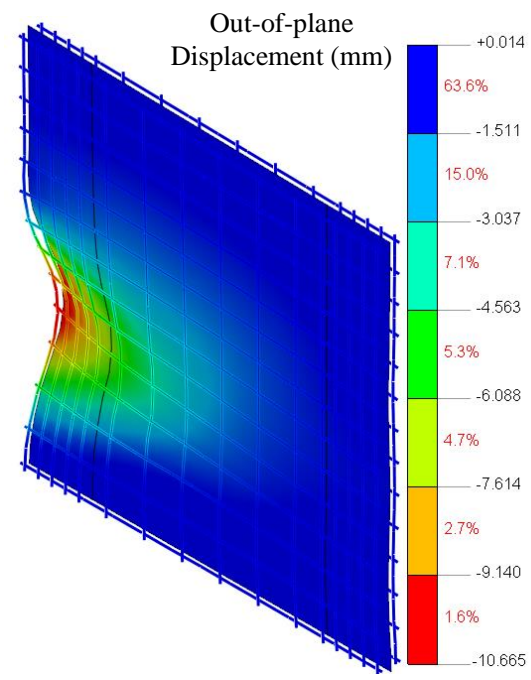

(b)

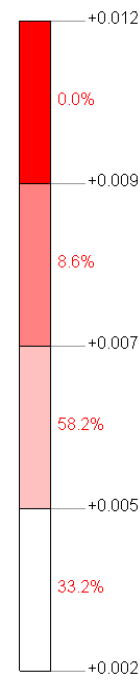

$+0.002$ (a)



Figure 6: L/H=1.0, SL26: (a) Distribution of vertical strains post-yielding at the onset of OOP deformation; (b) OOP deformation. 


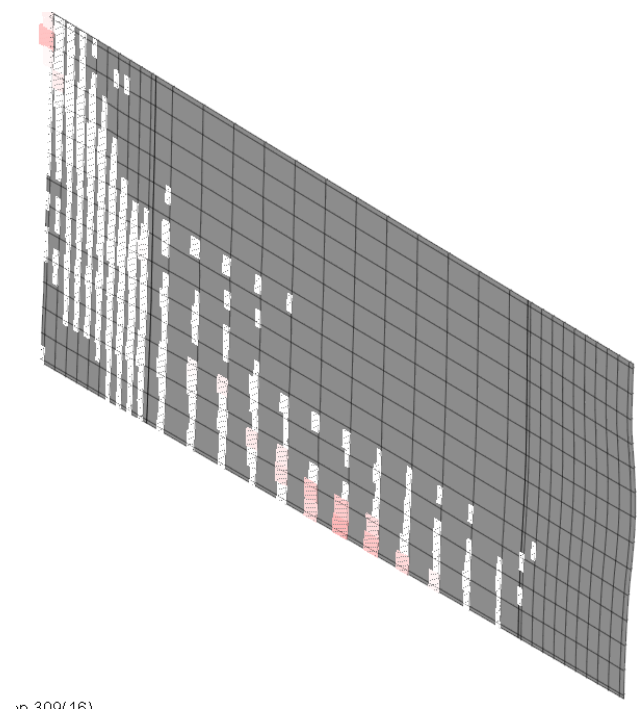

(a)

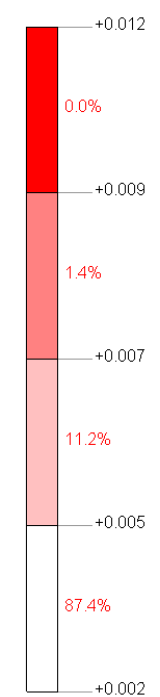

$+0.002$

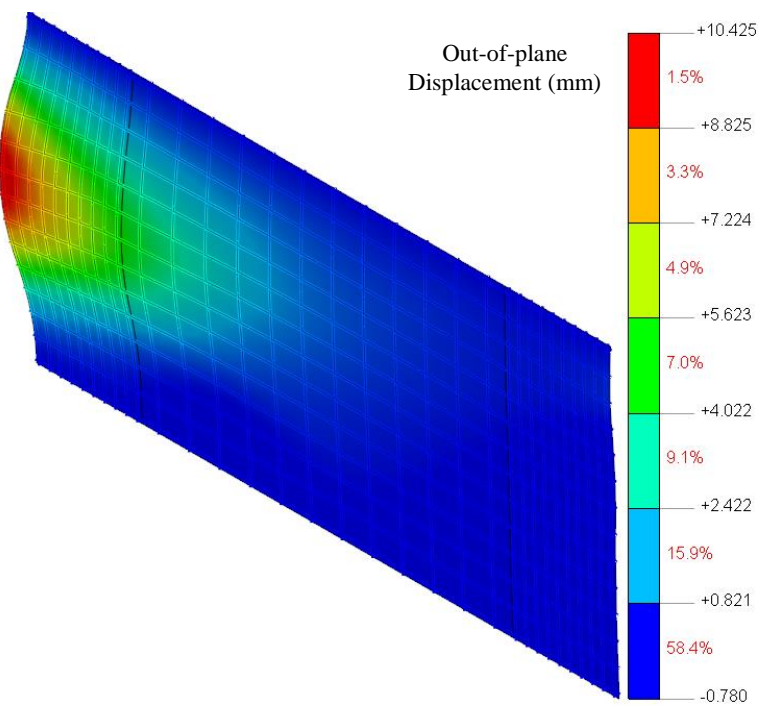

(b)

Figure 7: L/H=2.0, SL26: (a) Distribution of vertical strains above yield strain at the onset of OOP deformation; (b) OOP deformation.

As can be seen in Figure 7, the strain distribution of the model with $\mathrm{L} / \mathrm{H}=2.0$ is rather uniform along the 1 st storey height. Therefore, the strain distribution and OOP displacement profile of the model with $\mathrm{L} / \mathrm{H}=2.0$ resemble the ones of isolated boundary zones tested under uniaxial tension and compression cycles to study the OOP response of walls [43] . Hence, the difference between the OOP response of walls and boundary zones due to the disparity in the strain gradients along the unsupported height would not be very significant when the $\mathrm{L} / \mathrm{H}$ ratio is greater than or equal to 2.0. It should be noted that all these cases correspond to a constant shear-span ratio of 3.0, i.e., the effective height increases with increase of wall length. The increase of wall length without the variation of wall height would generate a lower shear-span ratio and understandably result in further contribution of shear distortion to the total displacement of the wall. The critical distribution of vertical strain along the height of boundary zone would therefore reach at a later drift and its development may even be suppressed by progression of shear failure.

\section{NEW EXPRESSIONS TO LIMIT THE TENSILE STRAIN DEMANDS}

Based on the results of the parametric study described above, an empirical equation (Equation 13) is developed for calculation of the critical strain at the elevation of maximum OOP displacement. This equation correlates this strain with the boundary region longitudinal reinforcement ratio, $\rho$, slenderness ratio, $\mathrm{H} / \mathrm{t}$, and the length-to-unsupported height ratio, $\mathrm{L} / \mathrm{H}$. Using the relationship between the critical strain at the elevation of maximum OOP displacement and the corresponding drift level for different $\mathrm{L} / \mathrm{H}$ ratios (Equation 12), Equation 13 can be rearranged as Equation 14. This equation calculates the required slenderness ratio for a desired drift level corresponding to the development of critical strain in the wall boundary regions. However, as mentioned in Section 2.2, the parameters that affect the OOP response of walls were classified into: i) slenderness (unsupported height-to-thickness) ratio; ii) the parameters that govern the vertical strain history and vertical strain gradients (e.g. axial load, wall length, longitudinal reinforcement ratio, concrete strength, loading history, shear-span ratio, etc.) and iii) OOP boundary conditions and different sources of eccentricity. The qualitative effects of these parameters were described in detail in Section 2.2. The most influential parameters that proved to exhibit a clear trend in terms of the OOP response of walls were considered in the numerical parametric study conducted herein and have been included in Equations 13 and 14. Therefore, some assumptions had to be made regarding the remaining parameters. For instance, the OOP rotation at the storey level was considered to be fixed in the numerical model. It is well understood that the type of constraint provided by the storey floor system against OOP rotation at the storey level does comply with neither the fully fixed nor the hinged boundary conditions. Also, the normal concrete strength (equal to $35 \mathrm{MPa}$ ) was considered in this study while relatively high concrete strength could influence the OOP response of walls [41]. Therefore, based on the numerical and experimental parametric investigations conducted by Dashti et al [31,35], Equation 14 is multiplied by a coefficient equal to 0.8 to include the potential effects of the remaining parameters. Equation 15 is thus considered as the ultimate relationship proposed for the slenderness limit.

$$
\begin{aligned}
\varepsilon_{c r} & =\frac{500 \alpha \varepsilon_{y}}{\sqrt{\rho}\left(\frac{H}{t}\right)^{2}} \\
\frac{H}{t} & =\frac{\alpha}{\sqrt{D} \rho^{0.25}} \\
\frac{H}{t} & =\frac{0.8 \alpha}{\sqrt{D} \rho^{0.25}}
\end{aligned}
$$

where,

$\mathrm{D}=$ drift level

$\alpha=\frac{H}{L}$ for $\frac{L}{H} \leq 2$ and $\alpha=0.5$ for $\frac{L}{H}>2$

Table 2 to Table 7 present the prediction of the critical strain and the wall thickness using the proposed equations (Equation 13 and 15) for different wall specimens and parametric models that were simulated using the numerical model in a previous parametric study [31] and the parametric models investigated in this study. The critical strains predicted by the numerical model are compared with the values calculated by Equation 13 and the analytical models proposed in the literature $[3,5]$. The wall thickness calculated by Equation 15 for different drift levels are also compared with the minimum thickness requirement of the New Zealand Concrete Design Standard (Equation 9). 
Table 2: Critical strain and thickness predictions of the proposed model; various test specimens and parametric models [31].

\begin{tabular}{|c|c|c|c|c|c|c|c|c|c|c|c|c|c|c|c|c|c|c|c|}
\hline & \multirow{3}{*}{ Specimen } & \multirow{3}{*}{$\stackrel{\mathrm{L}}{(\mathrm{mm})}$} & \multirow{3}{*}{$\underset{(\mathrm{mm})}{\mathrm{H}}$} & \multirow{3}{*}{$\stackrel{\mathrm{t}}{(\mathrm{mm})}$} & \multirow{3}{*}{$\mathrm{L} / \mathrm{H} \mathrm{H} / \mathrm{t}$} & \multirow{3}{*}{$\mathrm{M} / \mathrm{VL}$} & \multirow{3}{*}{$v$} & \multirow{3}{*}{$\begin{array}{c}\mathrm{BE}_{\rho_{\mathrm{v}}} \\
(\%)\end{array}$} & \multirow{3}{*}{$\begin{array}{l}\text { Stability } \\
\text { Criterion } \\
\mathrm{OOP}=\xi_{\mathrm{c}} \times \mathrm{t} \\
(\mathrm{mm})\end{array}$} & \multicolumn{5}{|c|}{ Normalized Critical Strain $\left(\varepsilon_{c r} / \varepsilon_{y}\right)$} & \multicolumn{5}{|c|}{ Minimum Thickness Requirement (mm) } \\
\hline & & & & & & & & & & \multicolumn{2}{|c|}{ Numerical } & \multirow{2}{*}{ Proposed } & \multirow{2}{*}{$\begin{array}{l}\text { Paulay \& } \\
\text { Priestley }\end{array}$} & \multirow{2}{*}{$\begin{array}{l}\text { Chai \& } \\
\text { Elayer }\end{array}$} & \multirow{2}{*}{$\begin{array}{c}\text { NZS310: } \\
2006\end{array}$} & \multicolumn{4}{|c|}{ Proposed } \\
\hline & & & & & & & & & & $\varepsilon_{c r} / \varepsilon_{y}$ & \begin{tabular}{|l|} 
Drift \\
$(\%)$
\end{tabular} & & & & & $\begin{array}{r}\text { Drift } \\
1.0 \% \\
\end{array}$ & \begin{tabular}{|l|} 
Drift \\
$1.5 \%$ \\
\end{tabular} & \begin{tabular}{|l|} 
Drift \\
$2.0 \%$ \\
\end{tabular} & \begin{tabular}{|r} 
Drift \\
$2.5 \%$ \\
\end{tabular} \\
\hline 1 & PW4 & 3048 & 3658 & 152.4 & 0.824 & 42 & 0.12 & 3.5 & 17.7 & 9.0 & $\begin{array}{l}2.5 \\
\left(1^{\text {st }}\right)\end{array}$ & 5.6 & 5.9 & 7.8 & 159 & 165 & 201 & 233 & 260 \\
\hline 2 & PW4-A & 3048 & 3658 & 152.4 & 0.824 & $4 \quad 2$ & 0.06 & 3.5 & 17.7 & 6.8 & $\begin{array}{l}2.0 \\
\left(1^{\text {st }}\right)\end{array}$ & 5.6 & 5.9 & 7.8 & 159 & 165 & 201 & 233 & 260 \\
\hline 3 & $\begin{array}{c}\text { PW4-A- } \\
\mathrm{Re}\end{array}$ & 3048 & 3658 & 152.4 & 0.824 & 42 & 0.06 & 1.8 & 26.0 & 9.6 & 2.5 (1st) & 7.9 & 8.7 & 10.1 & 115 & 139 & 170 & 196 & 219 \\
\hline 4 & PW4-A-T & 3048 & 3658 & 162.4 & 0.823 & 32 & 0.06 & 3.3 & 19.6 & 7.4 & $\begin{array}{c}2.5 \\
\text { (2nd) }\end{array}$ & 6.5 & 7.0 & 8.7 & 159 & 163 & 199 & 229 & 256 \\
\hline 5 & PW4-A-L & 4000 & 3658 & 152.4 & $\begin{array}{ll}1.124\end{array}$ & $4 \quad 2$ & 0.06 & 3.5 & 17.7 & 5.7 & $\begin{array}{c}1.5 \\
(1 \mathrm{st})\end{array}$ & 4.2 & 3.4 & 5.8 & 208 & 216 & 265 & 306 & 343 \\
\hline 6 & $\mathrm{R} 2$ & 1905 & 4572 & 101.6 & 0.445 & $\begin{array}{ll}5 \quad 2.4 \\
\end{array}$ & 0.00 & 4.0 & 14.3 & 5.3 & $\begin{array}{c}1.7 \\
(1 \mathrm{st})\end{array}$ & 3.0 & 6.9 & 8.6 & 91 & 106 & 130 & 150 & 169 \\
\hline 7 & $\mathrm{R} 2-\mathrm{Re}$ & 1905 & 4572 & 101.6 & 0.445 & $5 \quad 2.4$ & 0.00 & 2.0 & 20.1 & 7.5 & $\begin{array}{c}2.3 \\
\text { (3rd) }\end{array}$ & 4.2 & 9.8 & 10.9 & 73 & 90 & 110 & 126 & 141 \\
\hline 8 & R2-T & 1905 & 4572 & 111.6 & 0.441 & $\begin{array}{ll}1 \quad 2.4 \\
\end{array}$ & 0.00 & 4.0 & 15.7 & 5.6 & $\begin{array}{c}1.8 \\
\text { (1st) }\end{array}$ & 3.6 & 8.4 & 9.8 & 91 & 106 & 130 & 150 & 169 \\
\hline 9 & RW2-L & 2000 & 3660 & 102 & 0.536 & 63 & 0.09 & 2.9 & 14.7 & 8.3 & $\begin{array}{c}2.2 \\
(2 n d) \\
\end{array}$ & 4.2 & 5.5 & 7.5 & 106 & 104 & 126 & 146 & 164 \\
\hline 10 & $\operatorname{Re} 1$ & 2000 & 2000 & 125 & 1.016 & 63 & 0.05 & 1.3 & 30.8 & $N A^{*}$ & $\mathrm{NA}^{*}$ & 17.1 & 18.5 & 18.1 & 81 & 85 & 104 & 120 & 134 \\
\hline 11 & $\mathrm{Re} 2$ & 2000 & 2000 & 125 & 1.016 & 63 & 0.05 & 2.6 & 23.4 & 14.0 & $\begin{array}{c}2.5 \\
\text { (3rd) } \\
\end{array}$ & 12.1 & 14.1 & 14.4 & 90 & 100 & 123 & 143 & 159 \\
\hline 12 & $\operatorname{Re} 3$ & 2000 & 2000 & 125 & 1.016 & 63 & 0.05 & 5.2 & 16.3 & 11.5 & $\begin{array}{c}2.5 \\
\text { (2nd) }\end{array}$ & 8.6 & 9.8 & 11.0 & 118 & 120 & 146 & 169 & 189 \\
\hline 13 & $\mathrm{~T} 1$ & 2000 & 2000 & 110 & 1.018 & $8 \quad 3$ & 0.05 & 3.0 & 19.2 & 11.5 & $\begin{array}{c}2.0 \\
(1 \mathrm{st})\end{array}$ & 8.7 & 10.2 & 11.3 & 93 & 104 & 128 & 148 & 165 \\
\hline 14 & T2 & 2000 & 2000 & 125 & 1.016 & 63 & 0.05 & 2.6 & 23.4 & 14.0 & $\begin{array}{c}2.5 \\
\text { (3rd) }\end{array}$ & 12.1 & 14.1 & 14.4 & 90 & 100 & 123 & 143 & 159 \\
\hline 15 & Full Scale & 4000 & 4000 & 250 & 1.016 & 63 & 0.05 & 2.6 & 46.7 & 15.3 & $\begin{array}{c}2.5 \\
\text { (3rd) }\end{array}$ & 12.1 & 14.1 & 14.4 & 179 & 201 & 246 & 284 & 318 \\
\hline 16 & L3 & 1600 & 2000 & 125 & 0.816 & $\begin{array}{ll}6 & 3.75\end{array}$ & 0.05 & 4.3 & 18.1 & 12.6 & $\begin{array}{c}3.0 \\
\text { (3rd) }\end{array}$ & 11.8 & 17.1 & 16.9 & 84 & 91 & 111 & 129 & 144 \\
\hline 17 & L4 & 2000 & 2000 & 125 & 1.016 & 63 & 0.05 & 2.6 & 23.4 & 14.0 & $\begin{array}{c}2.5 \\
(3 \mathrm{rd})\end{array}$ & 12.1 & 14.1 & 14.4 & 90 & 100 & 123 & 143 & 159 \\
\hline 18 & L5 & 2400 & 2000 & 125 & 1.216 & $\begin{array}{ll}6 \quad 2.5 \\
6\end{array}$ & 0.04 & 2.6 & 23.4 & 12.6 & $\begin{array}{l}2.0 \\
(3 \mathrm{rd})\end{array}$ & 10.1 & 9.8 & 10.9 & 108 & 120 & 148 & 170 & 190 \\
\hline
\end{tabular}

L : Length; H: Unsupported Height; t: Thickness; L/t: Cross-Sectional Aspect Ratio; H/t: Slenderness Ratio; M/VL=Shear-span Ratio; v: Axial Load Ratio=N/f ${ }_{\mathrm{c}} \mathrm{A}_{\mathrm{g}} ; \rho_{\mathrm{v}}$ : Reinforcement Ratio (vertical); $\mathrm{A}_{\mathrm{s}}$ : Area of one Longitudinal Bar; $\varepsilon_{\mathrm{sm}}$ : Maximum Tensile Strain within a Cycle at the Elevation of Maximum OOP; OOP: Maximum OOP Displacement. * The wall exhibited shear failure.

Table 3: Critical strain and thickness predictions of the proposed model; L/H=1, Re Ratio 0.052.

\begin{tabular}{|c|c|c|c|c|c|c|c|c|c|c|c|c|c|c|c|c|c|c|c|c|}
\hline & \multirow{3}{*}{ Specimen } & \multirow{3}{*}{$\stackrel{\mathrm{L}}{(\mathrm{mm})}$} & \multirow{3}{*}{$\underset{(\mathrm{mm})}{\mathrm{H}}$} & \multirow{3}{*}{$\stackrel{\mathrm{t}}{\mathrm{t}}$} & \multirow{3}{*}{$\mathrm{L} / \mathrm{H}$} & \multirow{3}{*}{$\mathrm{H} / \mathrm{t} \mathrm{I}$} & \multirow{3}{*}{$M / V L$} & \multirow{3}{*}{$v$} & \multirow{3}{*}{$\begin{array}{l}\mathrm{BE} \rho_{\mathrm{v}} \\
(\%)\end{array}$} & \multirow{3}{*}{$\begin{array}{c}\text { Stability } \\
\text { Criterion } \\
\text { OOP }=\xi_{c} \times \\
t \\
(\mathrm{~mm})\end{array}$} & \multicolumn{5}{|c|}{ Normalized Critical Strain $\left(\varepsilon_{c r} / \varepsilon_{y}\right)$} & \multicolumn{5}{|c|}{$\begin{array}{l}\text { Minimum Thickness Requirement } \\
\qquad(\mathrm{mm})\end{array}$} \\
\hline & & & & & & & & & & & \multicolumn{2}{|c|}{ Numerical } & \multirow{2}{*}{ Proposed } & \multirow{2}{*}{$\begin{array}{l}\text { Paulay \& } \\
\text { Priestley }\end{array}$} & \multirow{2}{*}{$\begin{array}{l}\text { Chai \& } \\
\text { Elayer }\end{array}$} & \multirow{2}{*}{$\begin{array}{l}\text { NZS310: } \\
2006\end{array}$} & \multicolumn{4}{|c|}{ Proposed } \\
\hline & & & & & & & & & & & $\varepsilon_{c r} / \varepsilon_{y}$ & $\begin{array}{l}\begin{array}{l}\text { Drift } \\
(\%)\end{array} \\
\end{array}$ & & & & & $\begin{array}{c}\text { Drift } \\
1.0 \% \\
\end{array}$ & $\begin{array}{l}\text { Drift } \\
1.5 \% \\
\end{array}$ & $\begin{array}{l}\text { Drift } \\
2.0 \% \\
\end{array}$ & $\begin{aligned} \text { Drift } \\
2.5 \% \\
\end{aligned}$ \\
\hline 19 & SL26 & 2000 & 2000 & 77 & 1.0 & 26 & 3 & 0.05 & 5.2 & 10.0 & 5.3 & 0.78 & 3.3 & 3.7 & 6.0 & 118 & 120 & 146 & 169 & 189 \\
\hline 20 & SL24 & 2000 & 2000 & 83 & 1.0 & 24 & 3 & 0.05 & 5.2 & 10.8 & 5.2 & 0.95 & 3.8 & 4.3 & 6.5 & 118 & 120 & 146 & 169 & 189 \\
\hline 21 & SL22 & 2000 & 2000 & 90 & 1.0 & 22 & 3 & 0.05 & 5.2 & 11.7 & 6.1 & 1.15 & 4.4 & 5.1 & 7.1 & 118 & 120 & 146 & 169 & 189 \\
\hline 22 & SL20 & 2000 & 2000 & 100 & 1.0 & 20 & 3 & 0.05 & 5.2 & 13.0 & 8.5 & 1.57 & 5.5 & 6.3 & 8.1 & 118 & 120 & 146 & 169 & 189 \\
\hline 23 & SL18 & 2000 & 2000 & 110 & 1.0 & 18 & 3 & 0.05 & 5.2 & 14.3 & 10.0 & 1.96 & 6.6 & 7.6 & 9.2 & 118 & 120 & 146 & 169 & 189 \\
\hline 24 & SL16 & 2000 & 2000 & 125 & 1.0 & 16 & 3 & 0.05 & 5.2 & 16.3 & 13.9 & 2.75 & 8.6 & 9.8 & 11.0 & 118 & 120 & 146 & 169 & 189 \\
\hline 25 & SL14 & 2000 & 2000 & 145 & 1.0 & 14 & 3 & 0.05 & 5.2 & 18.9 & 17.7 & 3.42 & 11.5 & 13.2 & 13.7 & 118 & 120 & 146 & 169 & 189 \\
\hline 26 & SL12 & 2000 & 2000 & 165 & 1.0 & 12 & 3 & 0.05 & 5.2 & 21.5 & 23.1 & 4.64 & 14.9 & 17.1 & 16.9 & 118 & 120 & 146 & 169 & 189 \\
\hline 27 & SL10 & 2000 & 2000 & 200 & 1.0 & 10 & 3 & 0.05 & 5.2 & 26.0 & $N A^{*}$ & $N A^{*}$ & 21.9 & 25.1 & 23.4 & 118 & 120 & 146 & 169 & 189 \\
\hline
\end{tabular}


Table 4: Critical strain and thickness predictions of the proposed model; $L / H=2$, Re Ratio 0.052 .

\begin{tabular}{|c|c|c|c|c|c|c|c|c|c|c|c|c|c|c|c|c|c|c|c|c|}
\hline & \multirow{3}{*}{ Specimen } & \multirow{3}{*}{$\stackrel{\mathrm{L}}{(\mathrm{mm})}$} & \multirow{3}{*}{$\underset{(\mathrm{mm})}{\mathrm{H}}$} & \multirow{3}{*}{$\stackrel{\mathrm{t}}{\mathrm{t}}$} & \multirow{3}{*}{$\mathrm{L} / \mathrm{H}$} & \multirow{3}{*}{$\mathrm{H} / \mathrm{t}$} & \multirow{3}{*}{$\mathrm{M} / \mathrm{VL}$} & \multirow{3}{*}{$v$} & \multirow{3}{*}{$\begin{array}{l}\mathrm{BE} \rho_{\mathrm{v}} \\
(\%)\end{array}$} & \multirow{3}{*}{$\begin{array}{c}\text { Stability } \\
\text { Criterion } \\
\text { OOP }=\xi_{\mathrm{c}} \times \\
\mathrm{t} \\
(\mathrm{mm})\end{array}$} & \multicolumn{5}{|c|}{ Normalized Critical Strain $\left(\varepsilon_{c r} / \varepsilon_{y}\right)$} & \multicolumn{5}{|c|}{$\begin{array}{l}\text { Minimum Thickness Requirement } \\
\text { (mm) }\end{array}$} \\
\hline & & & & & & & & & & & \multicolumn{2}{|c|}{ Numerical } & \multirow{2}{*}{ Proposed } & \multirow{2}{*}{$\begin{array}{l}\text { Paulay \& } \\
\text { Priestley }\end{array}$} & \multirow{2}{*}{$\begin{array}{l}\text { Chai \& } \\
\text { Elayer }\end{array}$} & \multirow{2}{*}{$\begin{array}{l}\text { NZS310: } \\
2006\end{array}$} & \multicolumn{4}{|c|}{ Proposed } \\
\hline & & & & & & & & & & & $\varepsilon_{c r} / \varepsilon_{y}$ & $\begin{array}{l}\text { Drift } \\
(\%)\end{array}$ & & & & & \begin{tabular}{r|r|} 
Drift \\
$1.0 \%$ \\
\end{tabular} & $\begin{aligned} \text { Drift } \\
1.5 \% \\
\end{aligned}$ & $\begin{aligned} \text { Drift } \\
2.0 \% \\
\end{aligned}$ & \begin{tabular}{|l|} 
Drift \\
$2.5 \%$ \\
\end{tabular} \\
\hline 28 & SL28 & 4000 & 2000 & 71 & 2.0 & 28 & 3 & 0.03 & 5.2 & 9.2 & 1.6 & 0.18 & 1.4 & 0.8 & 3.6 & 236 & 239 & 293 & 338 & 378 \\
\hline 29 & SL26 & 4000 & 2000 & 77 & 2.0 & 26 & 3 & 0.03 & 5.2 & 10.0 & 2.3 & 0.34 & 1.6 & 0.9 & 3.8 & 236 & 239 & 293 & 338 & 378 \\
\hline 30 & SL24 & 4000 & 2000 & 83 & 2.0 & 24 & 3 & 0.03 & 5.2 & 10.8 & 3.4 & 0.38 & 1.9 & 1.1 & 3.9 & 236 & 239 & 293 & 338 & 378 \\
\hline 31 & SL22 & 4000 & 2000 & 90 & 2.0 & 22 & 3 & 0.03 & 5.2 & 11.7 & 3.9 & 0.46 & 2.2 & 1.3 & 4.0 & 236 & 239 & 293 & 338 & 378 \\
\hline 32 & SL20 & 4000 & 2000 & 100 & 2.0 & 20 & 3 & 0.03 & 5.2 & 13.0 & 4.7 & 0.55 & 2.7 & 1.6 & 4.3 & 236 & 239 & 293 & 338 & 378 \\
\hline 33 & SL19 & 4000 & 2000 & 105 & 2.0 & 19 & 3 & 0.03 & 5.2 & 13.7 & 5.1 & 0.64 & 3.0 & 1.7 & 4.4 & 236 & 239 & 293 & 338 & 378 \\
\hline 34 & SL18 & 4000 & 2000 & 110 & 2.0 & 18 & 3 & 0.03 & 5.2 & 14.3 & 5.4 & 0.69 & 3.3 & 1.9 & 4.5 & 236 & 239 & 293 & 338 & 378 \\
\hline 35 & SL17 & 4000 & 2000 & 118 & 2.0 & 17 & 3 & 0.03 & 5.2 & 15.4 & 6.2 & 0.78 & 3.8 & 2.2 & 4.8 & 236 & 239 & 293 & 338 & 378 \\
\hline 36 & SL16 & 4000 & 2000 & 125 & 2.0 & 16 & 3 & 0.03 & 5.2 & 16.3 & 7.1 & 0.82 & 4.3 & 2.5 & 5.0 & 236 & 239 & 293 & 338 & 378 \\
\hline 37 & SL15 & 4000 & 2000 & 135 & 2.0 & 15 & 3 & 0.03 & 5.2 & 17.6 & 7.7 & 0.95 & 5.0 & 2.9 & 5.3 & 236 & 239 & 293 & 338 & 378 \\
\hline 38 & SL14 & 4000 & 2000 & 145 & 2.0 & 14 & 3 & 0.03 & 5.2 & 18.9 & 8.7 & 1.06 & 5.8 & 3.3 & 5.7 & 236 & 239 & 293 & 338 & 378 \\
\hline 39 & SL13 & 4000 & 2000 & 155 & 2.0 & 13 & 3 & 0.03 & 5.2 & 20.2 & 9.5 & 1.15 & 6.6 & 3.8 & 6.1 & 236 & 239 & 293 & 338 & 378 \\
\hline 40 & SL12 & 4000 & 2000 & 165 & 2.0 & 12 & 3 & 0.03 & 5.2 & 21.5 & 10.9 & 1.25 & 7.5 & 4.3 & 6.5 & 236 & 239 & 293 & 338 & 378 \\
\hline 41 & SL11 & 4000 & 2000 & 180 & 2.0 & 11 & 3 & 0.03 & 5.2 & 23.4 & 13.0 & 1.51 & 8.9 & 5.1 & 7.1 & 236 & 239 & 293 & 338 & 378 \\
\hline 42 & SL10 & 4000 & 2000 & 200 & 2.0 & 10 & 3 & 0.03 & 5.2 & 26.0 & 16.9 & 1.90 & 11.0 & 6.3 & 8.1 & 236 & 239 & 293 & 338 & 378 \\
\hline
\end{tabular}

Table 5: Critical strain and thickness predictions of the proposed model; $L / H=2$, Re Ratio 0.026.

\begin{tabular}{|c|c|c|c|c|c|c|c|c|c|c|c|c|c|c|c|c|c|c|c|c|}
\hline & \multirow{3}{*}{ Specimen } & \multirow{3}{*}{$\underset{(\mathrm{mm})}{\mathrm{L}}$} & \multirow{3}{*}{$\underset{(\mathrm{mm})}{\mathrm{H}}$} & \multirow{3}{*}{$\stackrel{t}{\mathrm{t}}$} & \multirow{3}{*}{$\mathrm{L} / \mathrm{H}$} & \multirow{3}{*}{$\mathrm{H} / \mathrm{t}$} & \multirow{3}{*}{$\mathrm{M} / \mathrm{VL}$} & \multirow{3}{*}{$v$} & \multirow{3}{*}{$\begin{array}{l}\mathrm{BE} \rho_{v} \\
(\%)\end{array}$} & \multirow{3}{*}{$\begin{array}{c}\text { Stability } \\
\text { Criterion } \\
\text { OOP }=\xi_{\mathrm{c}} \times \\
\mathrm{t} \\
(\mathrm{mm})\end{array}$} & \multicolumn{5}{|c|}{ Normalized Critical Strain $\left(\varepsilon_{c r} / \varepsilon_{y}\right)$} & \multicolumn{5}{|c|}{$\begin{array}{l}\text { Minimum Thickness Requirement } \\
\qquad(\mathrm{mm})\end{array}$} \\
\hline & & & & & & & & & & & \multicolumn{2}{|c|}{ Numerical } & \multirow{2}{*}{ Proposed } & \multirow{2}{*}{$\begin{array}{l}\text { Paulay \& } \\
\text { Priestley }\end{array}$} & \multirow{2}{*}{$\begin{array}{l}\text { Chai \& } \\
\text { Elayer }\end{array}$} & \multirow{2}{*}{$\begin{array}{l}\text { NZS310: } \\
2006\end{array}$} & \multicolumn{4}{|c|}{ Proposed } \\
\hline & & & & & & & & & & & $\varepsilon_{c r} / \varepsilon_{y}$ & $\begin{array}{l}\text { Drift } \\
(\%)\end{array}$ & & & & & \begin{tabular}{r|} 
Drift \\
$1.0 \%$ \\
\end{tabular} & $\begin{aligned} \text { Drift } \\
1.5 \% \\
\end{aligned}$ & $\begin{array}{l}\text { Drift } \\
2.0 \%\end{array}$ & $\begin{aligned} \text { Drift } \\
2.5 \% \\
\end{aligned}$ \\
\hline 43 & SL26 & 4000 & 2000 & 77 & 2.0 & 26 & 3 & 0.03 & 2.6 & 14.4 & 3.9 & 0.36 & 2.3 & 1.3 & 4.1 & 179 & 201 & 246 & 284 & 318 \\
\hline 44 & SL24 & 4000 & 2000 & 83 & 2.0 & 24 & 3 & 0.03 & 2.6 & 15.5 & 4.2 & 0.42 & 2.7 & 1.6 & 4.3 & 179 & 201 & 246 & 284 & 318 \\
\hline 45 & SL22 & 4000 & 2000 & 90 & 2.0 & 22 & 3 & 0.03 & 2.6 & 16.8 & 4.2 & 0.52 & 3.1 & 1.8 & 4.5 & 179 & 201 & 246 & 284 & 318 \\
\hline 46 & SL20 & 4000 & 2000 & 100 & 2.0 & 20 & 3 & 0.03 & 2.6 & 18.7 & 5.6 & 0.64 & 3.9 & 2.3 & 4.8 & 179 & 201 & 246 & 284 & 318 \\
\hline 47 & SL18 & 4000 & 2000 & 110 & 2.0 & 18 & 3 & 0.03 & 2.6 & 20.6 & 6.0 & 0.73 & 4.7 & 2.7 & 5.2 & 179 & 201 & 246 & 284 & 318 \\
\hline 48 & SL16 & 4000 & 2000 & 125 & 2.0 & 16 & 3 & 0.03 & 2.6 & 23.4 & 10.5 & 0.96 & 6.1 & 3.5 & 5.9 & 179 & 201 & 246 & 284 & 318 \\
\hline 49 & SL14 & 4000 & 2000 & 145 & 2.0 & 14 & 3 & 0.03 & 2.6 & 27.1 & 12.0 & 1.35 & 8.1 & 4.7 & 6.8 & 179 & 201 & 246 & 284 & 318 \\
\hline 50 & SL12 & 4000 & 2000 & 165 & 2.0 & 12 & 3 & 0.03 & 2.6 & 30.8 & 17.0 & 1.68 & 10.6 & 6.1 & 8.0 & 179 & 201 & 246 & 284 & 318 \\
\hline 51 & SL10 & 4000 & 2000 & 200 & 2.0 & 10 & 3 & 0.03 & 2.6 & 37.4 & 23.4 & 2.36 & 15.5 & 9.0 & 10.3 & 179 & 201 & 246 & 284 & 318 \\
\hline
\end{tabular}

Table 6: Critical strain and thickness predictions of the proposed model; $L / H=2$, Re Ratio 0.013 .

\begin{tabular}{|c|c|c|c|c|c|c|c|c|c|c|c|c|c|c|c|c|c|c|c|c|}
\hline & \multirow{3}{*}{ Specimen } & \multirow{3}{*}{$\stackrel{\mathrm{L}}{(\mathrm{mm})}$} & \multirow{3}{*}{$\underset{(\mathrm{mm})}{\mathrm{H}}$} & \multirow{3}{*}{$\begin{array}{c}\mathrm{t} \\
(\mathrm{mm})\end{array}$} & \multirow{3}{*}{\multicolumn{2}{|c|}{$\mathrm{L} / \mathrm{H} \mathrm{H/t}$}} & \multirow{3}{*}{$\mathrm{M} / \mathrm{VL}$} & \multirow{3}{*}{$v$} & \multirow{3}{*}{$\begin{array}{l}\mathrm{BE} \rho_{v} \\
(\%)\end{array}$} & \multirow{3}{*}{$\begin{array}{c}\text { Stability } \\
\text { Criterion } \\
\text { OOP }=\xi_{\mathrm{c}} \times \\
\mathrm{t} \\
(\mathrm{mm})\end{array}$} & \multicolumn{5}{|c|}{ Normalized Critical Strain $\left(\varepsilon_{c r} / \varepsilon_{y}\right)$} & \multicolumn{5}{|c|}{$\begin{array}{l}\text { Minimum Thickness Requirement } \\
\qquad(\mathrm{mm})\end{array}$} \\
\hline & & & & & & & & & & & \multicolumn{2}{|c|}{ Numerical } & \multirow{2}{*}{ Proposed } & \multirow{2}{*}{$\begin{array}{l}\text { Paulay \& } \\
\text { Priestley }\end{array}$} & \multirow{2}{*}{$\begin{array}{l}\text { Chai \& } \\
\text { Elayer }\end{array}$} & \multirow{2}{*}{$\begin{array}{l}\text { NZS310: } \\
2006\end{array}$} & \multicolumn{4}{|c|}{ Proposed } \\
\hline & & & & & & & & & & & $\varepsilon_{c r} / \varepsilon_{y}$ & $\begin{array}{l}\begin{array}{l}\text { Drift } \\
(\%)\end{array} \\
\end{array}$ & & & & & \begin{tabular}{r|r|} 
Drift \\
$1.0 \%$ \\
\end{tabular} & \begin{tabular}{r|} 
Drift \\
$1.5 \%$ \\
\end{tabular} & \begin{tabular}{r|} 
Drift \\
$2.0 \%$ \\
\end{tabular} & $\begin{array}{r}\text { Drift } \\
2.5 \% \\
\end{array}$ \\
\hline 52 & SL26 & 4000 & 2000 & 77 & 2.0 & 26 & 3 & 0.03 & 1.3 & 18.9 & 3.9 & 0.38 & 3.3 & 1.8 & 4.4 & 163 & 169 & 206 & 239 & 268 \\
\hline 53 & SL24 & 4000 & 2000 & 83 & 2.0 & 24 & 3 & 0.03 & 1.3 & 20.4 & 6.8 & 0.45 & 3.8 & 2.0 & 4.7 & 163 & 169 & 206 & 239 & 268 \\
\hline 54 & SL22 & 4000 & 2000 & 90 & 2.0 & 22 & 3 & 0.03 & 1.3 & 22.1 & 5.4 & 0.56 & 4.4 & 2.4 & 5.0 & 163 & 169 & 206 & 239 & 268 \\
\hline 55 & SL20 & 4000 & 2000 & 100 & 2.0 & 20 & 3 & 0.03 & 1.3 & 24.6 & 7.9 & 0.68 & 5.5 & 3.0 & 5.4 & 163 & 169 & 206 & 239 & 268 \\
\hline 56 & SL18 & 4000 & 2000 & 110 & 2.0 & 18 & 3 & 0.03 & 1.3 & 27.1 & 9.2 & 0.88 & 6.6 & 3.6 & 5.9 & 163 & 169 & 206 & 239 & 268 \\
\hline 57 & SL16 & 4000 & 2000 & 125 & 2.0 & 16 & 3 & 0.03 & 1.3 & 30.8 & 13.4 & 1.21 & 8.6 & 4.6 & 6.8 & 163 & 169 & 206 & 239 & 268 \\
\hline 58 & SL14 & 4000 & 2000 & 145 & 2.0 & 14 & 3 & 0.03 & 1.3 & 35.7 & 15.3 & 1.6 & 11.5 & 6.2 & 8.1 & 163 & 169 & 206 & 239 & 268 \\
\hline 59 & SL12 & 4000 & 2000 & 165 & 2.0 & 12 & 3 & 0.03 & 1.3 & 40.6 & 20.9 & 2.11 & 14.9 & 8.1 & 9.6 & 163 & 169 & 206 & 239 & 268 \\
\hline 60 & SL10 & 4000 & 2000 & 200 & 2.0 & 10 & 3 & 0.03 & 1.3 & 49.2 & 33.8 & 3.15 & 21.9 & 11.9 & 12.6 & 163 & 169 & 206 & 239 & 268 \\
\hline
\end{tabular}


Table 7: Critical strain and thickness predictions of the proposed model; $L / H=3$, Re Ratio 0.052.

\begin{tabular}{|c|c|c|c|c|c|c|c|c|c|c|c|c|c|c|c|c|c|c|c|c|}
\hline & \multirow{3}{*}{ Specimen } & \multirow{3}{*}{$\underset{(\mathrm{mm})}{\mathrm{L}}$} & \multirow{3}{*}{$\underset{(\mathrm{mm})}{\mathrm{H}}$} & \multirow{3}{*}{$\stackrel{\mathrm{t}}{(\mathrm{mm})}$} & \multirow{3}{*}{\multicolumn{2}{|c|}{$\mathrm{L} / \mathrm{H} \mathrm{H} / \mathrm{t}$}} & \multirow{3}{*}{$\mathrm{M} / \mathrm{VL}$} & \multirow{3}{*}{$v$} & \multirow{3}{*}{$\begin{array}{l}\mathrm{BE} \rho_{\mathrm{v}} \\
(\%)\end{array}$} & \multirow{3}{*}{$\begin{array}{c}\text { Stability } \\
\text { Criterion } \\
\begin{array}{c}\mathrm{OOP}=\xi_{\mathrm{c}} \times \\
\mathrm{t} \\
(\mathrm{mm})\end{array}\end{array}$} & \multicolumn{5}{|c|}{ Normalized Critical Strain $\left(\varepsilon_{c r} / \varepsilon_{y}\right)$} & \multicolumn{5}{|c|}{$\begin{array}{l}\text { Minimum Thickness Requirement } \\
\qquad(\mathrm{mm})\end{array}$} \\
\hline & & & & & & & & & & & \multicolumn{2}{|c|}{ Numerical } & \multirow{2}{*}{ Proposed } & \multirow{2}{*}{$\begin{array}{l}\text { Paulay \& } \\
\text { Priestley }\end{array}$} & \multirow{2}{*}{$\begin{array}{l}\text { Chai \& } \\
\text { Elayer }\end{array}$} & \multirow{2}{*}{$\begin{array}{l}\text { NZS310: } \\
2006\end{array}$} & \multicolumn{4}{|c|}{ Proposed } \\
\hline & & & & & & & & & & & $\varepsilon_{c r} / \varepsilon_{y}$ & $\begin{array}{l}\text { Drift } \\
(\%)\end{array}$ & & & & & $\begin{aligned} \text { Drift } \\
1.0 \% \\
\end{aligned}$ & $\begin{array}{l}\text { Drift } \\
1.5 \%\end{array}$ & $\begin{array}{c}\text { Drift } \\
2.0 \%\end{array}$ & $\begin{array}{l}\text { Drift } \\
2.5 \%\end{array}$ \\
\hline 61 & SL28 & 6000 & 2000 & 71 & 3.0 & 28 & 3 & 0.05 & 5.2 & 9.2 & 3.3 & 0.21 & 1.4 & 0.4 & 3.3 & 284 & 239 & 293 & 338 & 378 \\
\hline 62 & SL26 & 6000 & 2000 & 77 & 3.0 & 26 & 3 & 0.05 & 5.2 & 10.0 & 2.8 & 0.25 & 1.6 & 0.4 & 3.3 & 284 & 239 & 293 & 338 & 378 \\
\hline 63 & SL24 & 6000 & 2000 & 83 & 3.0 & 24 & 3 & 0.05 & 5.2 & 10.8 & 3.6 & 0.28 & 1.9 & 0.5 & 3.4 & 284 & 239 & 293 & 338 & 378 \\
\hline 64 & SL22 & 6000 & 2000 & 90 & 3.0 & 22 & 3 & 0.05 & 5.2 & 11.7 & 3.6 & 0.33 & 2.2 & 0.6 & 3.5 & 284 & 239 & 293 & 338 & 378 \\
\hline 65 & SL20 & 6000 & 2000 & 100 & 3.0 & 20 & 3 & 0.05 & 5.2 & 13.0 & 4.7 & 0.46 & 2.7 & 0.7 & 3.6 & 284 & 239 & 293 & 338 & 378 \\
\hline 66 & SL18 & 6000 & 2000 & 110 & 3.0 & 18 & 3 & 0.05 & 5.2 & 14.3 & 5.9 & 0.6 & 3.3 & 0.8 & 3.7 & 284 & 239 & 293 & 338 & 378 \\
\hline 67 & SL16 & 6000 & 2000 & 125 & 3.0 & 16 & 3 & 0.05 & 5.2 & 16.3 & 7.8 & 0.71 & 4.3 & 1.1 & 3.9 & 284 & 239 & 293 & 338 & 378 \\
\hline 68 & SL14 & 6000 & 2000 & 145 & 3.0 & 14 & 3 & 0.05 & 5.2 & 18.9 & 9.7 & 0.86 & 5.8 & 1.5 & 4.2 & 284 & 239 & 293 & 338 & 378 \\
\hline 69 & SL12 & 6000 & 2000 & 165 & 3.0 & 12 & 3 & 0.05 & 5.2 & 21.5 & 13.4 & 1.22 & 7.5 & 1.9 & 4.5 & 284 & 239 & 293 & 338 & 378 \\
\hline 70 & SL10 & 6000 & 2000 & 200 & 3.0 & 10 & 3 & 0.05 & 5.2 & 26.0 & 17.0 & 1.5 & 11.0 & 2.8 & 5.3 & 284 & 239 & 293 & 338 & 378 \\
\hline
\end{tabular}

Figure 8 displays the comparison of the critical strain predicted by the proposed model and by other analytical models with the numerical model results. As also discussed in Section 2.1, the theoretical plastic hinge length (Equation 4) was assumed to be the buckling length in the analytical models proposed by Paulay and Priestley [3] and Chai and Elayer [5]. The effect of variation of the buckling length from the plastic hinge length to the numerically simulated buckling length $(60-70 \%$ of the unsupported height), denoted as modified $l_{o}$, is also indicated in
Figure 8. As shown in this figure, the analytical models proposed by Paulay and Priestley [3] and Chai and Elayer [5] for $\mathrm{L} / \mathrm{H}$ ratios of 2 and 3 result in similar strain limitations when the value of the buckling length in these models is replaced by $60-70 \%$ of the unsupported height. The variation trend of the modified Paulay and Priestley model seems to be in better agreement with the numerical model and its predicted strains are very close to those of the proposed model for these $\mathrm{L} / \mathrm{H}$ ratios.
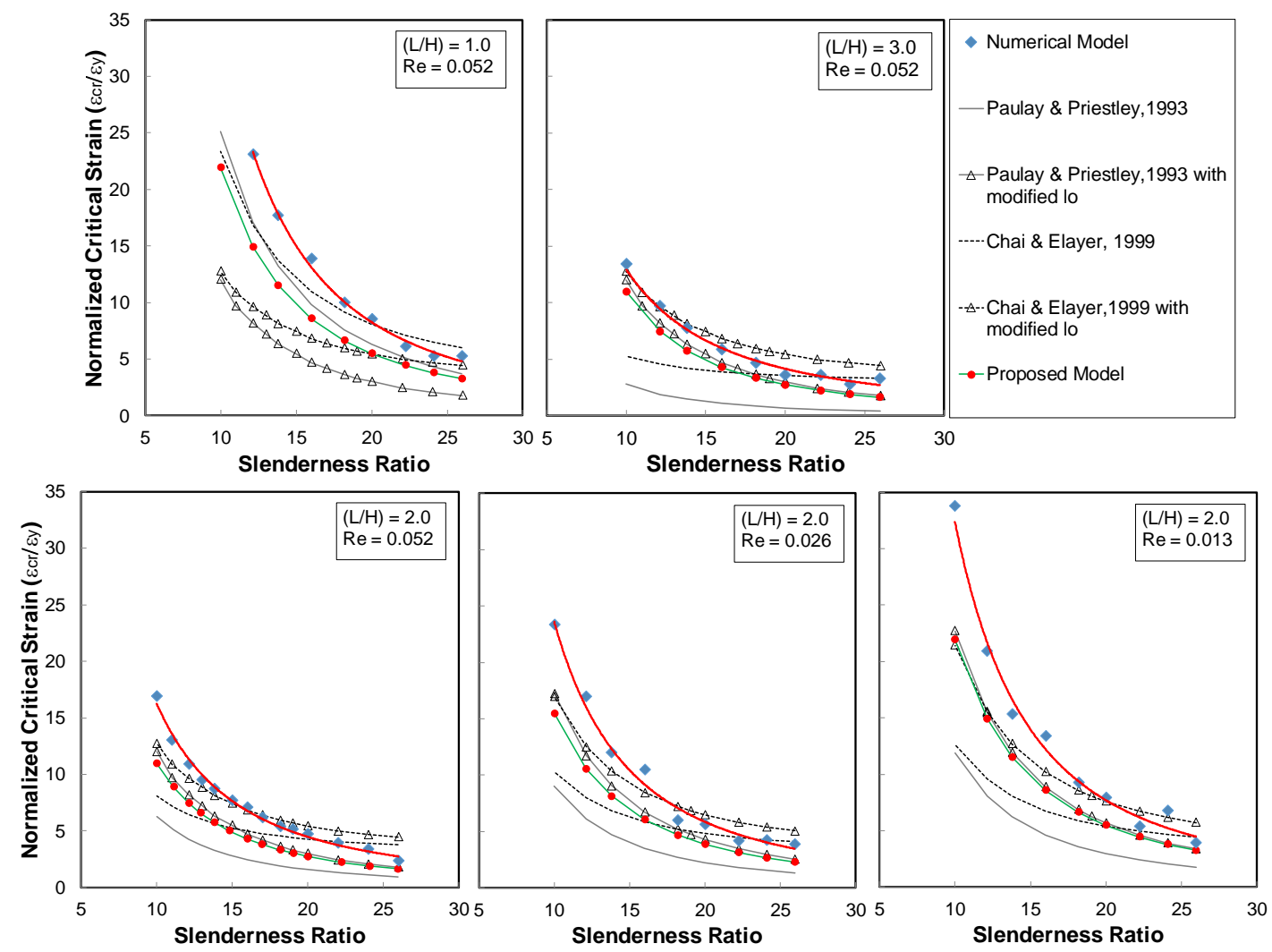

Figure 8: Normalized critical strain vs slenderness ratio predicted by the numerical model and different analytical models.

As for $\mathrm{L} / \mathrm{H}=1$, the analytical models (with the assumption of buckling length equal to the plastic hinge length) are in better agreement with the numerical results compared to the modified analytical models. The modified models, however, result in more conservative prediction of the critical strain for a given slenderness ratio. This is while this modification leads to less conservative prediction of the critical strain when the $\mathrm{L} / \mathrm{H}$ ratio is equal to or greater than 2.0. This disparity can be attributed to the fact that the wall length is one of the key parameters in the theoretical length of plastic hinge (Equation 4). It is interesting to note that the plastic hinge length is assumed to be equal to half of the wall length in the New Zealand concrete design standard (NZS3101:2006-A3 [42]). Therefore, as the wall length exceeds two times the unsupported height, the 
buckling length (if assumed to be equal to the plastic hinge length) will go beyond the unsupported height. The resultant OOP displacement will therefore be significantly larger as compared to a buckling length equivalent to $60-70 \%$ of the unsupported height. This uniqueness is considered in the current design provisions relevant to OOP instability by a coefficient $\left(\mathrm{k}_{\mathrm{m}}\right.$, Equation 10) to reduce the predicted thickness for walls with plastic hinge length beyond the unsupported height $\left(\mathrm{h}_{\mathrm{n}}\right.$, Equation 10). The value of $\left(0.25+0.055 \mathrm{~A}_{\mathrm{r}}\right) \mathrm{L}_{\mathrm{w}}$ in Equation 10 would be in the order of and slightly larger than that given by the plastic hinge length equation proposed by Paulay and Priestley (Equation 4).

The proposed model predictions are conservative with respect to the numerical model predictions. This safety margin is incorporated in the model to compensate for the effects of parameters like geometric and material eccentricity as well as the OOP boundary conditions (representative of the effects of floor restraints) that are not taken into account. The effects of these parameters are studied by the authors [31] and the conservativeness of the proposed model appears to be sufficient considering their effects on the initiation stage and value of the OOP displacement.

The accuracy of the proposed equation with respect to the numerical model prediction is indicated in Figure 9a along with the predictions made by the former analytical models. As can be seen in this figure, the critical strain calculated by the proposed equation is below the numerical model prediction for all cases while the other analytical models overestimated this strain for a significant number of cases. In order to investigate this discrepancy, the critical strain calculations of the wall models investigated in this study to scrutinize the effects of boundary region longitudinal reinforcement and $\mathrm{L} / \mathrm{H}$ ratios are presented in different graphs (Figure 10). While the strain values predicted by the proposed equation and the analytical model proposed by Paulay and Priestley [3] are below the numerical model value (indicating their relatively conservative prediction), the equation proposed by Chai and Elayer [5] overestimates these strain values when the slenderness increases. It is interesting to note that the variation of the analytical/numerical strain ratio with slenderness for both the proposed model and the model by Paulay and Priestley [3] seems to follow an identical trend although the latter model significantly underestimates the critical strain with the increase of $\mathrm{L} / \mathrm{H}$. The proposed model predictions are generally around $60-90 \%$ of the numerical predictions for most cases. This relatively conservative prediction would allow for the uncertainties involved with the amount of geometric and material eccentricities as well as the OOP boundary conditions discussed by Dashti et al [31]. It should be noted that some of the models borrowed from the previous parametric study [31] were developed based on the test specimens that lacked OOP restraints at the storey level and therefore represented significantly large slenderness ratios. Also, some of these models were based on the test specimens that had hinged OOP support at the elevation of loading, making the models significantly susceptible to OOP instability. Specimens 1-9 represent these characteristics.

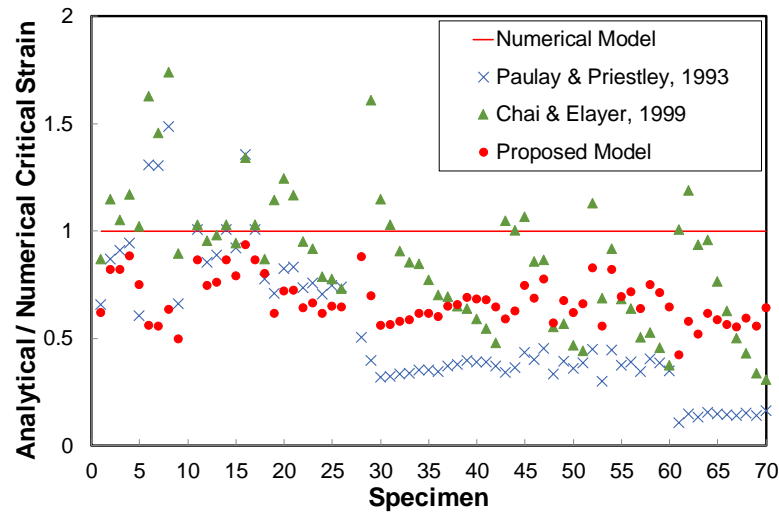

(a)

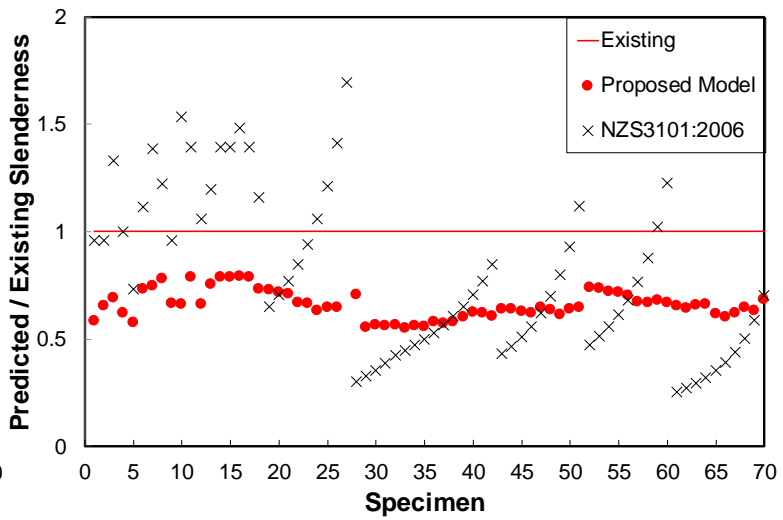

(b)

Figure 9: (a) Analytical/numerical critical strain with different models; (b) predicted/existing slenderness ratio with the proposed model and the NZS3101:2006 equation.

Figure $9 \mathrm{~b}$ compares the slenderness calculated by the proposed equation (Equation 15) with the existing slenderness of the wall models and the slenderness calculated according to NZS3101:2006 thickness requirement (Equation 9). The drift levels associated with the stability criterion of the numerical models were incorporated in Equation 12 for this comparison. As can be seen in this figure, the slenderness calculated by the proposed equation for the stability criterion drift levels of all the wall models are less than the existing slenderness. The NZS3101:2006 thickness requirement (Equation 9), however, results in higher slenderness requirements in a significant number of cases. In order to evaluate this discrepancy, the slenderness versus drift level plot of the proposed model is compared with the numerical predictions and the NZS3101:2006 slenderness requirement for the parametric models studied in this paper (Tables 2-6) in Figure 11.

Figure 11 shows the safety margin of the proposed model with respect to the numerical predictions for different drift levels. It also indicates that the effects of $\mathrm{L} / \mathrm{H}$ and boundary region reinforcement ratios are well captured by the proposed model. The thickness requirement of the NZS3101:2006 does not depend on the drift capacity of the wall and does therefore result in constant slenderness values. The intersection of numerical data with the slenderness line of NZS3101:2006 shows that the current thickness requirement of the New Zealand Concrete Design Standard is safe when the desired drift level for development of stability criterion is less than $2.0 \%$. Therefore, since the stability criterion of walls with $\mathrm{L} / \mathrm{H}=1$ reached at larger drift levels, this slenderness requirement was greater than the one corresponding to progression of large OOP displacements for these walls. However, it should be reminded that the numerical data is derived based on the fixed OOP rotation at the storey level, limited shear-span ratio and normal concrete strength (35 MPa). The safety margin of the proposed model is therefore considered to include the effects of these parameters. 

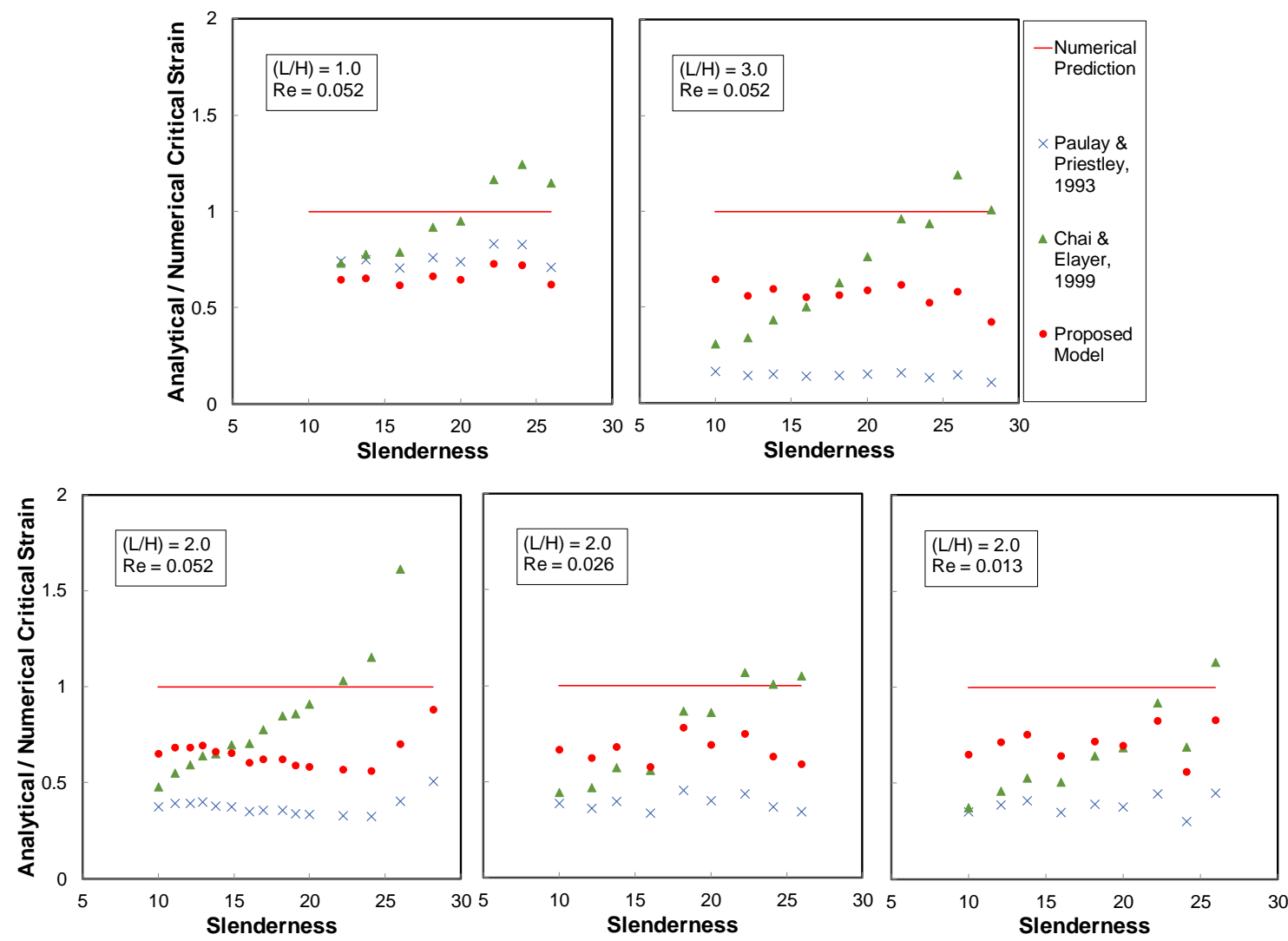

Figure 10: Analytical/numerical critical strain with different analytical models for walls with different L/H and boundary region longitudinal reinforcement ratios.
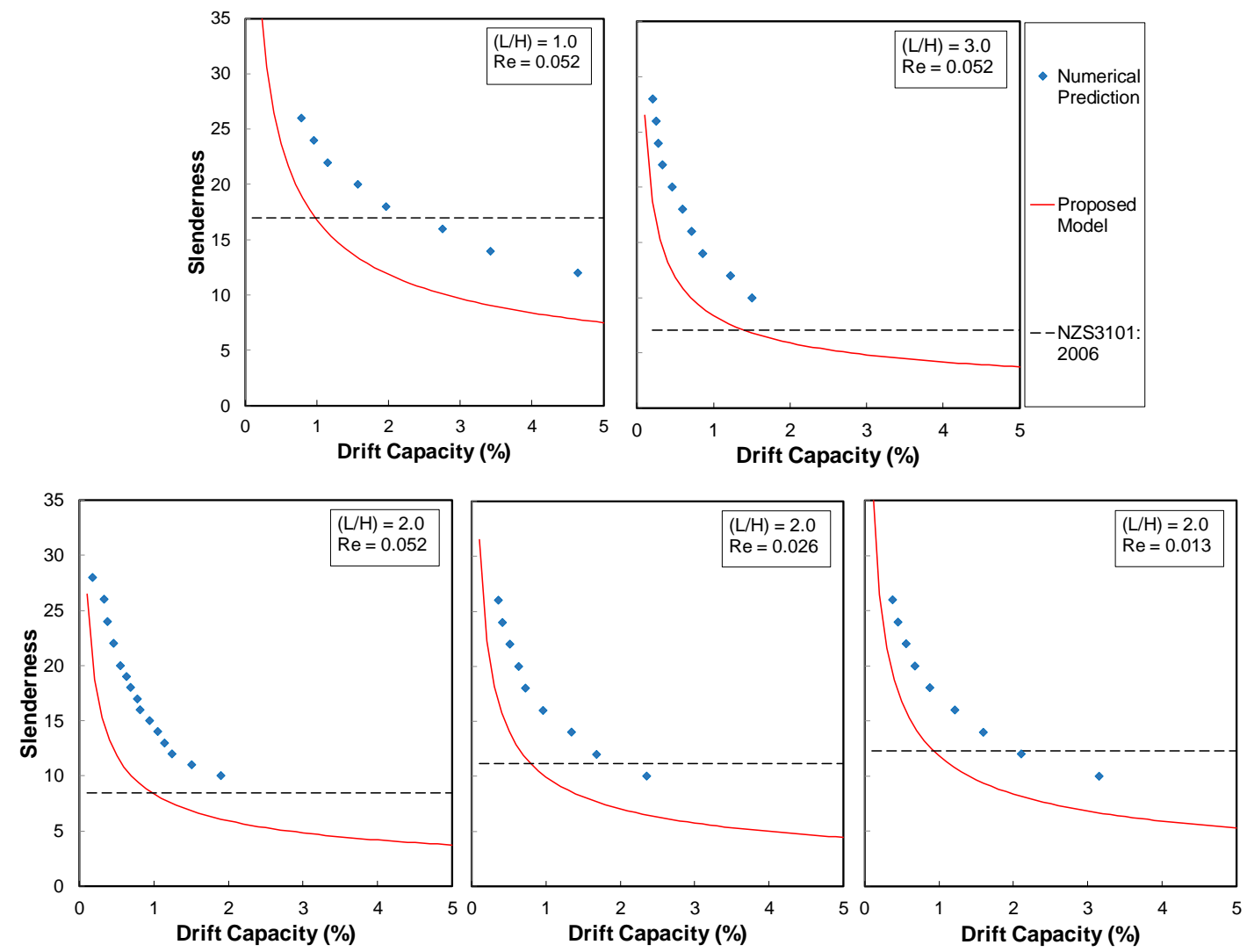

Figure 11: Predicted/existing slenderness ratio with the proposed model and the NZS3101:2006 equation for walls with different $L / H$ and boundary region longitudinal reinforcement ratios. 


\section{DISCUSSION AND CONCLUDING REMARKS}

A parametric investigation is conducted in this study in order to propose an equation to safeguard ductile structural walls against OOP instability. Among the measures that could be used to reduce the probability of OOP instability in rectangular walls, increasing the wall thickness, i.e. decreasing the slenderness (height-to-thickness) is the most efficient approach. Hence, lower slenderness would be required if the progression of OOP instability was to be prevented up to a higher drift level. Therefore, an equation is proposed to limit the wall slenderness ratio for a desired drift level. Other parameters incorporated in this equation include the boundary zone longitudinal reinforcement ratio and the length-to-unsupported height ratio. The discussion and concluding remarks around this parametric evaluation and the proposed model are listed below.

- The fully recoverable OOP deformation starts at early drift levels and the OOP displacement equivalent to the stability criterion proposed by Paulay and Priestley [3] results in residual OOP deformation. The global instability results in an abrupt and brittle mode of failure and has the potential to lead to collapse of the building. The initiation of development of residual OOP deformation is therefore considered as the design limit state in this study. Thus, the wall design shall aim for delaying the tensile strain corresponding to the above mentioned stability criterion (critical strain) until the desired drift level.

- The parametric study is conducted using a previously verified numerical model to quantitatively evaluate the sensitivity of the OOP response of flexure-dominated rectangular walls (shear-span ratio $=3.0$ ) to the parameters that have been identified to influence its progression. The variation of critical strain with respect to the change of slenderness (unsupported height-to-thickness), length and boundary region longitudinal reinforcement ratio exhibited a clear trend.

- The numerical predictions of this critical strain for the parametric wall models are compared with the predictions of the analytical models proposed in the literature. The analytical models resulted in a better match with the numerical predictions when the originally considered value of buckling length that (i.e. equal to the theoretical plastic hinge length) was modified to the numerically calculated value (60-70\% of the unsupported height).

- Based on the parametric study noted above, an empirical equation is proposed for calculation of the critical strain at the elevation of the maximum OOP displacement. This equation correlates the critical strain with slenderness (unsupported height-to-thickness), length-to-unsupported height and boundary region longitudinal reinforcement ratios. The relationship between this critical strain and the drift level is also derived using the numerical calculations. Using the empirical equation noted above and this relationship, an equation is derived (as below) for calculation of wall slenderness, $\mathrm{H} / \mathrm{t}$, for a given combination of drift level, D, boundary region longitudinal reinforcement ratio, $\rho$, and length-to-unsupported height ratio, $\mathrm{L} / \mathrm{H}$.

$$
\begin{array}{rlrl}
\frac{H}{t}=\frac{0.8 \alpha}{\sqrt{D} \rho^{0.25}} & \text { where, } & \alpha=\frac{H}{L} \text { for } \frac{L}{H} \leq 2 \\
\text { and } & \alpha=0.5 \text { for } \frac{L}{H}>2
\end{array}
$$

- The proposed equation is validated against the numerical model predictions and experimental observations in some well-confined ductile walls tested in the literature and their parametric models, as well as the parametric models generated and evaluated in this parametric study.
- The proposed equation is reasonably conservative to account for the effects of the parameters that are not included in the equation. Some of these parameters proved not to influence this mode of failure with a specific trend (such as axial load ratio), and some of them were not easy to be incorporated in the model (such as OOP boundary conditions at the storey level as well as the construction and material eccentricities) given the unpredictable extent of these parameters.

- The effect of unsupported height and desired drift levels (rotations) are not incorporated in the existing New Zealand Concrete Design Standard provision for prevention of OOP instability in walls. Therefore, the calculated slenderness requirement is found to be above the critical value for a number of cases, particularly when the unsupported height is larger than the commonly adopted values for the storey height (3-4m).

- The current minimum thickness requirement of NZS 3101:2006-A3 applies to walls with axial load ratios greater than $5 \%$. Given the mixed and complex effect of this parameter and experimental as well as numerical observation of OOP instability in walls with relatively low axial load ratios, the provisions for minimum thickness criteria for wall instability in NZS 3101:2006-A3 (Cl 11.4.3.2) should be extended to apply to walls with axial load ratios below $5 \%$ as well.

- Doubly-reinforced walls with well-confined boundary regions and rather large shear strength can develop large tensile strains along a decent height from the base before progression of other failure modes such as bar buckling, bar fracture and concrete crushing at the base and large diagonal cracks along the web. Such walls are more susceptible to global OOP instability.

- To reduce the likelihood of OOP deformation for a given slenderness ratio, replacement of a long wall with several short walls would be a better alternative than increasing the reinforcement ratio for a reduced length in a single wall.

\section{ACKNOWLEDGEMENTS}

The authors wish to acknowledge the financial support provided by the Building Systems Performance branch of the New Zealand Ministry of Business, Innovation and Employment (MBIE) and the Quake Centre at University of Canterbury to conduct this research.

\section{REFERENCES}

1 Sritharan S, Beyer K, Henry RS, Chai Y, Kowalsky M and Bull D (2014). "Understanding poor seismic performance of concrete walls and design implications". Earthquake Spectra, 30(1): 307-334. https://doi.org/10.1193/021713EQS036M

2 Paulay T and Goodsir W (1985). "The ductility of structural walls". Bulletin of the New Zealand Society for Earthquake Engineering, 18(3): 250-269. https://doi.org/10.5459/bnzsee.18.3.250-269

3 Paulay T and Priestley M (1993). "Stability of ductile structural walls". ACI Structural Journal, 90(4): 385-392.

4 NZS3101. (2006). "Concrete Structures Standard, NZS 3101:2006 Parts 1\&2 ", Standards New Zealand.

5 Chai YH and Elayer DT (1999). "Lateral stability of reinforced concrete columns under axial reversed cyclic tension and compression". ACI Structural Journal, 96(5): 780-789. 
6 Acevedo CE, Creagh A, Moehle J, Hassan W and Tanyeri A (2010). "Seismic Vulnerability of Non-special Boundary Element of Shear Wall under Axial Force Reversals". Florida International University and University of California Berkeley, USA.

7 Creagh A, Acevedo C, Moehle J, Hassan W and Tanyeri AC (2010). "Seismic Performance of Concrete Special Boundary Element". University of Texas at Austin and University of California Berkley, USA.

8 Chrysanidis T and Tegos I (2012). "The influence of tension strain of wall ends to their resistance against lateral instability for low-reinforced concrete walls". $15^{\text {th }}$ World Conference on Earthquake Engineering (15WCEE), Lisbon, Portugal.

9 Hilson C, Segura C and Wallace J (2014). "Experimental study of longitudinal reinforcement buckling in reinforced concrete structural wall boundary elements". Tenth US National Conference on Earthquake Engineering (10NCEE), Anchorage, Alaska.

10 Taleb R, Tani M and Kono S (2016). "Performance of confined boundary regions of RC walls under cyclic reversal loadings". Journal of Advanced Concrete Technology, 14(4): 108-124. https://doi.org/10.3151/jact.14.108

11 Welt TS, Massone LM, LaFave JM, Lehman DE, McCabe SL and Polanco P (2016). "Confinement behavior of rectangular reinforced concrete prisms simulating wall boundary elements". Journal of Structural Engineering, 143(4): 04016204. https://doi.org/10.1061/(ASCE)ST.1943-541X.0001682

12 Haro AG, Kowalsky M, Chai Y and Lucier GW (2018). "Boundary elements of special reinforced concrete walls tested under different loading paths". Earthquake Spectra, 34(3): 1267-1288. https://doi.org/10.1193/081617EQS160M

13 Rosso A, Jiménez-Roa LA, De Almeida JP, Zuniga APG, Blandón CA, Bonett RL and Beyer K (2018). "Cyclic tensile-compressive tests on thin concrete boundary elements with a single layer of reinforcement prone to outof-plane instability". Bulletin of Earthquake Engineering, 16(2): $859-887$ https://doi.org/10.1007/s10518-017-0228-1

14 Rosso A, Almeida JP and Beyer K (2016). "Stability of thin reinforced concrete walls under cyclic loads: state-of-theart and new experimental findings". Bulletin of Earthquake Engineering, 14(2): 455-484. https://doi.org/10.1007/s10518-015-9827-x

15 Oesterle R, Fiorato A, Johal L, Carpenter J, Russell H and Corley W (1976). "Earthquake Resistant Structural Walls: Tests of Isolated Walls". PCA Serial No. Report 1571, Research and Development Construction Technology Laboratories, Portland Cement Association.

16 Goodsir WJ (1985). "The Design of Coupled Frame-Wall Structures for Seismic Actions". PhD Dissertation, University of Canterbury. http://dx.doi.org/10.26021/2876

17 Thomsen IV JH and Wallace JW (1995). "Displacementbased design of reinforced concrete structural walls: An experimental investigation of walls with rectangular and $T$ shaped cross-sections". Report No. CU/CEE-95-06, Department of Civil and Environmental Engineering, Clarkson University, Potsdam, NY.

18 Johnson B (2010). "Anchorage detailing effects on lateral deformation components of $R / C$ shear walls". Master Thesis, University of Minnesota.

19 Rosso A, Almeida JP and Beyer K (2014). "Short report on the experimental cyclic test of a thin RC wall (TW1) for blind prediction purposes". Ecole Polytechnique Federale de Lausanne (EPFL).
20 Almeida J, Prodan O, Rosso A and Beyer K (2017). "Tests on thin reinforced concrete walls subjected to in-plane and out-of-plane cyclic loading". Earthquake Spectra, 33(1): 323-345. https://doi.org/10.1193/101915eqs154dp

21 Rosso A, Jiménez-Roa LA, Almeida JPD and Beyer K (2020). "Instability of thin concrete walls with a single layer of reinforcement under cyclic loading: Numerical simulation and improved equivalent boundary element model for assessment". Journal of Earthquake Engineering: 1-32.

https://doi.org/10.1080/13632469.2019.1691679

22 Menegon S, Wilson J, Gad E and Lam N (2015). "Out-ofplane buckling of limited ductile reinforced concrete walls under cyclic loads". NZSEE Annual Connference, Rotorua, New Zealand.

23 DIANA T (2011). "Finite Element Analysis User's Manual - Release 9.4.4", TNO DIANA.

24 Dashti F, Dhakal RP and Pampanin S (2014). "Simulation of out-of-plane instability in rectangular RC structural walls". Second European Conference on Earthquake Engineering and Seismology, Istanbul, Turkey.

25 Dashti F, Dhakal RP and Pampanin S (2017). "Numerical modeling of rectangular reinforced concrete structural walls". Journal of Structural Engineering, 143(6): 04017031.

https://doi.org/10.1061/(ASCE)ST.1943-541X.0001729

26 Dashti F, Dhakal RP and Pampanin S (2018). "Validation of a numerical model for prediction of out-of-plane instability in ductile structural walls under concentric inplane cyclic loading". Journal of Structural Engineering, 144(6): 04018039. https://doi.org/10.1061/(ASCE)ST.1943-541X.0002013

27 Dashti F, Dhakal RP and Pampanin S (2018). "Blind prediction of in-plane and out-of-plane responses for a thin singly reinforced concrete flanged wall specimen". Bulletin of Earthquake Engineering, 16(1): 427-458. https://doi.org/10.1007/s10518-017-0211-x

28 Dashti F, Dhakal RP and Pampanin S (2019). "A parametric investigation on applicability of the curved shell finite element model to nonlinear response prediction of planar RC walls". Bulletin of Earthquake Engineering, 17(12): 6515-6546. https://doi.org/10.1007/s10518-019-00582-8

29 Kolozvari K, Biscombe L, Dashti F, Dhakal RP, Gogus A, Gullu MF, Henry RS, Massone LM, Orakcal K, Rojas F, Shegay A and Wallace J (2019). "State-of-the-art in nonlinear finite element modeling of isolated planar reinforced concrete walls". Engineering Structures, 194: 46-65. https://doi.org/10.1016/j.engstruct.2019.04.097

30 Dashti F, Dhakal R and Pampanin S (2014). "Numerical simulation of shear wall failure mechanisms". Annual Conference of the New Zealand Society for Earthquake Engineering, Auckland, New Zealand.

31 Dashti F, Dhakal RP and Pampanin S (2020). "A parametric study on out-of-plane instability of doubly reinforced structural walls. Part I: FEM predictions". Bulletin of Earthquake Engineering, 18(6): 3747-3780. https://doi.org/10.1007/s10518-020-00828-w

32 Dashti F (2017). "Out-of-plane Instability of Rectangular Reinforced Concrete Walls Under In-plane Loading". PhD Thesis, Department of Civil and Natural Resources Engineering, University of Canterbury, 294pp.

33 Dashti F, Dhakal R and Pampanin S (2017). "An experimental study on out-of-plane deformations of rectangular structural walls subject to in-plane loading". Proceedings of the $16^{\text {th }}$ World Conference on Earthquake Engineering, Santiago, Chile. 
34 Dashti F, Dhakal RP and Pampanin S (2017). "Tests on slender ductile structural walls designed according to New Zealand standard". Bulletin of the New Zealand Society for Earthquake Engineering, 50(4): 504-516. https://doi.org/10.5459/bnzsee.50.4.504-516

35 Dashti F, Tripathi M, Dhakal RP and Pampanin S (2020). "A parametric study on out-of-plane instability of doubly reinforced structural walls. Part II: Experimental investigation". Bulletin of Earthquake Engineering, 18(11): 5193-5220. https://doi.org/10.1007/s10518-020-00898-w

36 Dashti F, Dhakal R and Pampanin S (2017). "Evaluation of New Zealand code requirements related to instability failure of structural walls". Annual Conference of the New Zealand Society for Earthquake Engineering, Wellington, New Zealand.

37 Dashti F, Dhakal RP and Pampanin S (2018). "Evolution of out-of-plane deformation and subsequent instability in rectangular RC walls under in-plane cyclic loading: Experimental observation". Earthquake Engineering and Structural Dynamics, 47(15): 2944-2964. https://doi.org/10.1002/eqe.3115

38 Dashti F, Dhakal R and Pampanin S (2020). "Out-of-plane response of in-plane-loaded ductile structural walls: Stateof-the-art and classification of the observed mechanisms". Journal of Earthquake Engineering. https://doi.org/10.1080/13632469.2020.1713928

39 Dashti F, Dhakal R and Pampanin S (2018). "Local vs global instability of ductile structural walls". Annual Conference of the New Zealand Society for Earthquake Engineering, Auckland, New Zealand.

40 Dashti F, Dhakal RP and Pampanin S. (2018). "Inelastic strain gradients in reinforced concrete structural walls". 16th European Conference on Earthquake Engineering, Thessaloniki, Greece.
41 Tripathi M, Dhakal RP and Dashti F (2020). "Nonlinear cyclic behaviour of high-strength ductile RC walls: Experimental and numerical investigations". Engineering Structures. https://doi.org/10.1016/j.engstruct.2020.111116

42 NZS3101:2006 (2017). "Concrete Structures Standard, Parts 1\&2 (Amendment No. 3)". Standards New Zealand.

43 Tripathi M, Dhakal RP, Dashti F and Gokhale R (2020). "Axial response of rectangular RC prisms representing the boundary elements of ductile concrete walls". Bulletin of Earthquake Engineering. 18: 4387-4420. https://doi.org/10.1007/s10518-020-00868-2

44 Elwood KJ (2013). "Performance of concrete buildings in the 22 February 2011 Christchurch earthquake and implications for Canadian codes". Canadian Journal of Civil Engineering, 40(3): 1-18. https://doi.org/10.1139/cjce-2011-0564

45 Wallace J (2012). "Behavior, design, and modeling of structural walls and coupling beams - Lessons from recent laboratory tests and earthquakes". International Journal of Concrete Structures and Materials, 6(1): 3-18. https://doi.org/10.1007/s40069-012-0001-4

46 Thomsen IV JH and Wallace JW (2004). "Displacementbased design of slender reinforced concrete structural wallsexperimental verification". Journal of Structural Engineering, 130(4): 618-630. https://doi.org/10.1061/(ASCE)07339445(2004)130:4(618) 